\title{
Analysis of the Bacterial and Fungal Community Profiles in Bulk Soil and Rhizospheres of Three Mungbean [Vigna radiata (L.) R. Wilczek] Genotypes through PCR-DGGE
}

\author{
Anna Mae M. de los Reyes ${ }^{1, a^{*}}$, Eureka Teresa M. Ocampo ${ }^{2, b}$, \\ Ma. Carmina C. Manuel ${ }^{3, c}$, Bernadette C. Mendoza ${ }^{4, d}$ \\ ${ }^{1}$ Plant Physiology Laboratory, Institute of Plant Breeding, Los Baños, Laguna, Philippines \\ ${ }^{2}$ Institute of Crop Science, University of the Philippines, Los Baños, Laguna, Philippines \\ ${ }^{3}$ Genetics and Molecular Biology Division, University of the Philippines, Los Baños, Laguna, \\ Philippines \\ ${ }^{4}$ Microbiology Division, University of the Philippines, Los Baños, Laguna, Philippines \\ aamdelosreyes4@up.edu.ph, bemocampo1@up.edu.ph, 'mcmanuel1@up.edu.ph, \\ dbcmendoza@up.edu.ph
}

\begin{abstract}
Keywords: multivariate analysis, diversity index, plant growth stage, rhizosphere effect, mungbean genotype effect
\end{abstract}

\begin{abstract}
Each plant species is regarded to substantially influence and thus, select for specific rhizosphere microbial populations. This is considered in the exploitation of soil microbial diversity associated with important crops, which has been of interest in modern agricultural practices for sustainable productivity. This study used PCR-DGGE (polymerase chain reaction - denaturing gradient gel electrophoresis) in order to obtain an initial assessment of the bacterial and fungal communities associated in bulk soil and rhizospheres of different mungbean genotypes under natural field conditions. Integrated use of multivariate analysis and diversity index showed plant growth stage as the primary driver of community shifts in both microbial groups while rhizosphere effect was found to be less discrete in fungal communities. On the other hand, genotype effect was not discerned but not inferred to be absent due to possible lack of manifestations of differences among genotypes based on tolerance to drought under non-stressed environment, and due to detection limits of DGGE. Sequence analysis of prominent members further revealed that Bacillus and Arthrobacter species were dominant in bacterial communities whereas members of Ascomycota and Basidiomycota were common in fungal communities of mungbean. Overall, fungal communities had higher estimated diversity and composition heterogeneity, and were more dynamic under plant growth influence, rhizosphere effect and natural environmental conditions during mungbean growth in upland field. These primary evaluations are prerequisite to understanding the interactions between plant and rhizosphere microorganisms with the intention of employing their potential use for sustainable crop production.
\end{abstract}

\section{Introduction}

The diversity of microbial communities in soil reflects the range of functions microorganisms partake in ecological processes that sustain life $[1,2]$. Critical roles of microorganisms encompass biogeochemical cycles and food chains, maintaining essential relationships among themselves and with higher order organisms [3], as well as soil formation [4]. It is well recognized then that soil microbial communities are essential contributors in the sustainability of terrestrial ecosystems $[5,6]$ and even as useful indicators of soil health $[7,8,9]$.

Rhizosphere microbes are particularly deemed major contributors for sustainable agriculture for they have strong correlations with plant health and growth [10]. It has been widely reported that plant species is one of the most important factors that shape these microbial communities in soil suggesting that plants are thought to be selective with their microbial populations [11-13]. 
Legumes (Fabaceae) are the second most functionally important plant group on the globe next to the grass family (Poaceae) [14]. The group includes mungbean, which has been transformed into a major crop in Asia for its value in supplementing human nutritional needs, improved soil productivity, and cost-efficient farming [15]. It is also the principal food legume in the Philippines in terms of land area and value of production [16]. Members of the legume family have been widely studied for plant-microbe interactions in the rhizosphere, owing to their agricultural significance and ability to form symbiotic relationships with rhizobia and arbuscular mycorrhizal fungi (AMF) [17]. Nevertheless, there has been limited characterization of rhizosphere community diversity that could affect legume-microbe symbioses for many members of the group including mungbean.

The objective of this research is to perform an initial assessment of the bacterial and fungal community structures associated with mungbean under natural field conditions by using PCRDGGE. It is intended to estimate how diverse these microorganisms are, to observe for and compare changes in bacterial and fungal community structures during mungbean growth, and to identify dominant community members. Results may serve as reference for future investigations such as understanding physiological functions of rhizosphere microorganisms, the impact of stress factors on the microbiological aspect of the legume and comparison with other plant-specific soil microbial community researches. Preliminary findings can also be augmented with other culture-dependent and modern metagenomic approaches.

\section{Theory}

Since soil microbial communities have both indubitable and potential functions not only in an environmental but also in agricultural and industrial perspectives, it is valuable to be able to routinely assess their diversity $[2,18]$. Amid the availability of modern metagenomic approaches, the fingerprinting technique denaturing gradient gel electrophoresis (DGGE) presents a costeffective method that has been useful for multiple and simultaneous microbial diversity estimation [19-21]. The approach provides a means to make spatial and/or temporal comparisons of soil communities from various locations or among treatments [21, 22] relevant for the current study. Diversity can be assessed by obtaining molecular profiles specific for a sample by combining PCR amplification of taxonomical targets from complex microbial community DNA with DGGE analysis of differences in sequences [22]. The use of target genes 16S rDNA for bacteria [23, 24] and internal transcribed spacer (ITS) for fungi $[25,26]$ has granted access to the examination of microbial communities to the extent of identifying its members. The structural diversity of bacteria and fungi are then described through the assessment of genetic fingerprints by combined use of clustering and principal components analysis as well as computation for diversity index.

\section{Materials and Methods}

Field Site Background. The field experiment was performed in upland soil condition during the transition from dry to rainy season (April through June 2016) at Tranca, Bay, Laguna, Philippines located at latitude $14^{\circ} 08^{\prime} 22^{\prime} \mathrm{N}$ and longitude $121^{\circ} 15^{\prime} 33^{\prime \prime} \mathrm{E}$ [27]. The land area (Figure 1) is found near the edge of Mount Makiling forest reserve and has been extensively used to grow a variety of vegetables and root crops since the 1980's. Typical harvests, which include okra, mungbean, squash, cassava and sweet potato are grown in no particular pattern at about month-long intervals. Farming practices in the site involve sourcing water from deep well reservoir for perforain and furrow irrigation systems, supplying nitrogen and potassium fertilizers, and using insecticides as needed. 


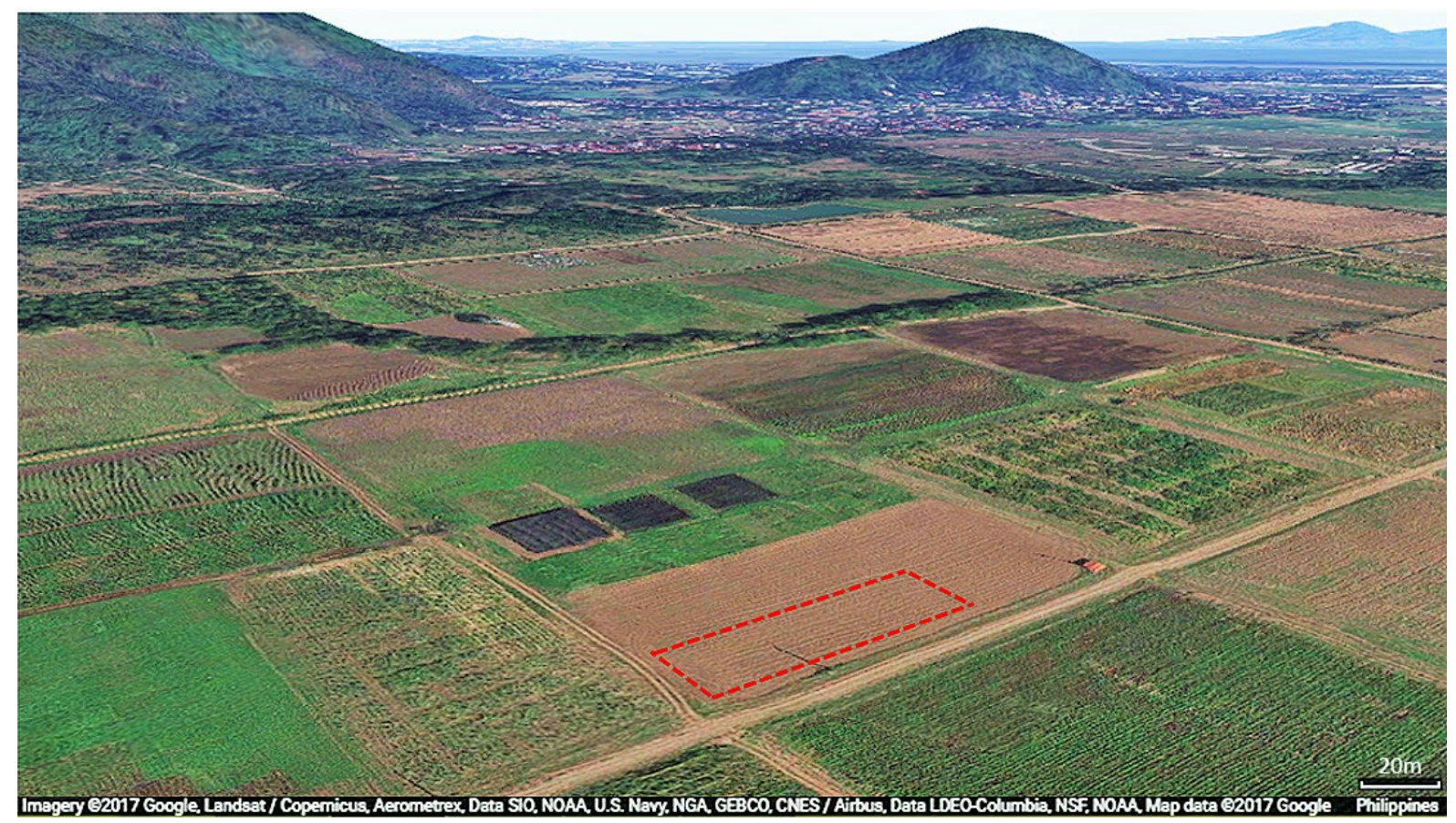

Figure 1. Field site experiment at Tranca, Bay, Laguna, Philippines (Imagery (C 2017 Google)

Mungbean Genotypes and Field Lay-out. A repeated measures (RM) in randomized complete block design (RCBD) was implemented wherein three mungbean genotypes were used based on their tolerance to drought stress. Seeds of Accession 831, Pag-asa 3 and Pag-asa 7 were obtained from the University of the Philippines Los Baños - Institute of Plant Breeding (UPLBIPB). Los Baños, Laguna. Pag-asa 7 has been found to endure low moisture conditions having relatively higher yields under such conditions. Accession 831 has been observed to be resilient to drought [28] while Pag-asa 3 is intolerant to the abiotic stress. Adjacent plots A and B comprised of nine $5 \times 5 \mathrm{~m}$ minor plots each (Figure 2), among which the three mungbean genotypes were randomly sown. The individual minor plots consisted of 10 rows in which 1000 seeds were equally distributed.

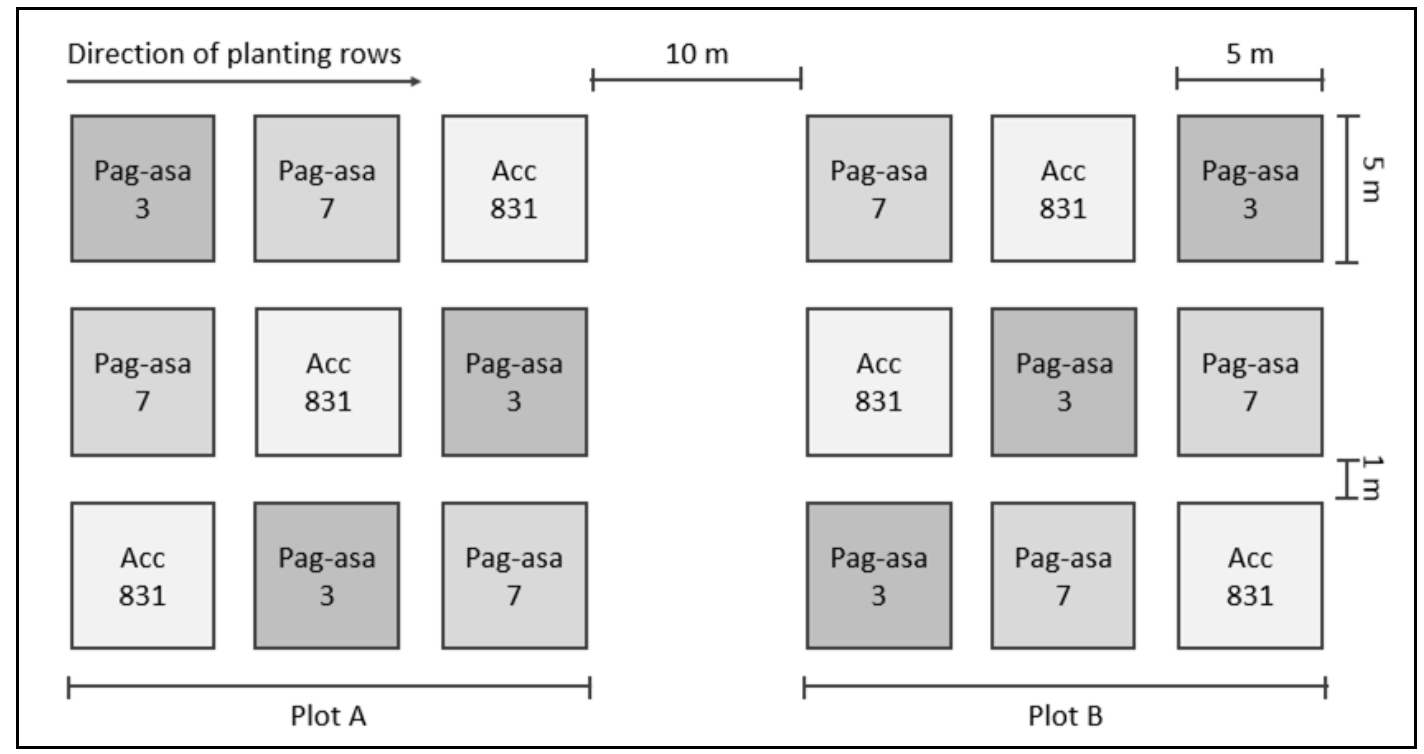

Figure 2. Experimental field lay-out: Accession (Acc) 831, Pag-asa 3 and Pag-asa 7 mungbean genotypes are sown following a randomized complete block design (RCBD) in two replicate plots A and B 
Soil Sample Collection. Sample collection of bulk and rhizosphere soils were performed during the flowering (35 days after sowing) and physiological maturity (57 days after sowing) developmental stages of mungbean. Bulk soil samples were collected by taking soil cores between rows of mungbeans at even depths of approximately $10 \mathrm{~cm}$. Five soil cores $(2 \mathrm{~cm}$ diameter) from different points per subplot were completely mixed together in polypropylene bags. Pooled soil from subplots planted with the same mungbean genotype were further combined together to obtain composite samples. An initial composite bulk soil sample from each of major plots A and B were also obtained before sowing to use as control. For rhizosphere soil, five plants per subplot were carefully excavated with which the roots were vigorously shaken to remove soil not tightly adhering to the roots. The remaining soil on the roots were then collected in polypropylene bags. Composite rhizosphere soil samples were prepared similarly as done for bulk soil collection. Three composite bulk soil and rhizosphere samples were acquired from each replicate plot at every sampling event. A total of 24 composite soil samples were taken from the two major plots for the two sampling times. Soil samples were placed in sealed container with ice during transport to the laboratory and were stored at $-20{ }^{\circ} \mathrm{C}$ prior to DNA extraction. Independent soil samples from the replicate plots were submitted to IPB Physiology Laboratory for physico-chemical analysis.

DNA Extraction from Bulk and Rhizosphere Soils. The CTAB (cetyl trimethyl ammonium bromide) with mannitol DNA extraction method described by Fatima et al. [29] was used with modifications for all soil samples. One gram of soil per sample was ground in liquid nitrogen and subsequently mixed with $2 \mathrm{~mL}$ extraction buffer comprising of $0.2 \mathrm{M}$ Tris- $\mathrm{HCl}(\mathrm{pH} 8.0), 0.02 \mathrm{M}$ $\mathrm{Na}_{2}$ EDTA ( $\mathrm{pH} 8.0$ ), $1.5 \mathrm{M} \mathrm{NaCl}, 10 \%$ SDS (sodium dodecyl sulfate), $0.5 \mathrm{M}$ mannitol and 1\% $\mathrm{CTAB}$. Samples were then incubated at $65{ }^{\circ} \mathrm{C}$ in water bath for $1 \mathrm{~h}$ with occasional stirring followed by centrifugation at $12,000 \mathrm{rpm}$ for $15 \mathrm{~min}$ at $4{ }^{\circ} \mathrm{C}$. The resulting supernatants were transferred to new tubes and added with equal volumes of $0.5 \mathrm{M} \mathrm{NaCl}$ and $0.5 \mathrm{M} \mathrm{CTAB}$. After incubation at room temperature for $10 \mathrm{~min}$, the samples were mixed with approximately equal volumes of chloroform:isoamyl alcohol (C:I) solution and centrifuged again at 12,000 rpm for $15 \mathrm{~min}$ at $4{ }^{\circ} \mathrm{C}$. The aqueous layers were precipitated by addition of isopropanol and by centrifugation using the same parameters in previous steps. Recovered pellets were washed with $95 \%$ ethanol, air dried and dissolved in $20 \mu \mathrm{L}$ TE-RNase $(1 \mathrm{mg} / \mathrm{mL})$ for $1 \mathrm{~h}$ at $37{ }^{\circ} \mathrm{C}$ water bath. The solution was spun down at $10,000 \mathrm{rpm}$ for $10 \mathrm{~min}$ prior to transferring $20 \mu \mathrm{L}$ supernatant to new tubes. Extracted DNA were kept at $-20^{\circ} \mathrm{C}$.

The quality and quantity of DNA samples were initially assessed through electrophoretic run on $1.0 \%$ (wt/vol) agarose gels along with a series of lambda $(\lambda)$ DNA standards. Direct nucleic acid concentration and purity (UV absorbance ratio at 260/280 nm) were determined using Epoch ${ }^{\mathrm{TM}}$ with Take3 ${ }^{\text {TM }}$ micro-volume plates (BioTek Instruments Inc., Winooski, VT, USA).

PCR Amplification from Bacterial 16S rDNA Genes. All primers used in the study are presented in Table 1. The PCR protocols performed for bacteria and fungi were based on recommended procedures by Valášková and Baldrian [30] with modifications. PCR was carried out in $25 \mu \mathrm{L}$ reaction mixtures, which contained 1X PCR buffer with $\mathrm{MgCl}_{2}, 0.1 \mathrm{mM}$ dNTPs, $0.1 \mu \mathrm{M}$ forward primer 968F-GC, $0.1 \mu \mathrm{M}$ reverse primer R1378, $0.5 \mathrm{U}$ Taq polymerase, $2.5 \mu \mathrm{L}$ DNA $(25-50 \mathrm{ng} / \mu \mathrm{L})$ template and sterile ultrapure $\mathrm{H}_{2} \mathrm{O}$ to bring to total volume. Cycling conditions included an initial denaturation of $94{ }^{\circ} \mathrm{C}$ for $2 \mathrm{~min}$, followed by 35 cycles of $92{ }^{\circ} \mathrm{C}$ for $30 \mathrm{~s}$ (denaturation), $55^{\circ} \mathrm{C}$ for $1 \mathrm{~min}$ (annealing), and $72{ }^{\circ} \mathrm{C}$ for $45 \mathrm{~s}$ (extension) with a final extension step at $72{ }^{\circ} \mathrm{C}$ for $5 \mathrm{~min}$.

PCR Amplification from Fungal ITS Regions. First PCR reaction consisted of 1X PCR buffer with $\mathrm{MgCl}_{2}(1.5 \mathrm{mM}), 0.1 \mathrm{mM}$ dNTPs, $0.1 \mu \mathrm{M}$ forward primer, $0.1 \mu \mathrm{M}$ reverse primer, $0.5 \mu \mathrm{g} / \mathrm{mL}$ bovine serum albumin (BSA), $0.5 \mathrm{U}$ Taq polymerase and $2.5 \mu \mathrm{L}$ DNA $(50 \mathrm{ng} / \mu \mathrm{L})$. Sterile ultrapure $\mathrm{H}_{2} \mathrm{O}$ was added to bring the total volume to $25 \mu \mathrm{L}$. The amplification cycle consisted of an initial denaturation step of $94{ }^{\circ} \mathrm{C}$ for $5 \mathrm{~min}$, followed by 35 cycles of $94{ }^{\circ} \mathrm{C}$ for $1 \mathrm{~min}, 50{ }^{\circ} \mathrm{C}$ for $1 \mathrm{~min}$, and $72{ }^{\circ} \mathrm{C}$ for $1 \mathrm{~min}$. Final extension step is at $72{ }^{\circ} \mathrm{C}$ for $10 \mathrm{~min}$.

Second PCR reaction used $2.5 \mu \mathrm{L}$ PCR product from the first reaction as DNA template for a $25 \mu \mathrm{L}$ mixture. Each reaction consisted of $1 \mathrm{X}$ PCR buffer with $\mathrm{MgCl}_{2}(1.5 \mathrm{mM}), 0.2 \mathrm{mM} \mathrm{dNTPs}$, 
$0.2 \mu \mathrm{M}$ forward primer, $0.2 \mu \mathrm{M}$ reverse primer, $0.1 \mu \mathrm{g} / \mathrm{mL}$ bovine serum albumin (BSA), $0.5 \mathrm{U}$ Taq polymerase and ultrapure $\mathrm{H}_{2} \mathrm{O}$ to bring to final volume. The amplification conditions comprised of an initial denaturation at $94{ }^{\circ} \mathrm{C}$ for $5 \mathrm{~min}, 40$ cycles of $94{ }^{\circ} \mathrm{C}$ for $30 \mathrm{~s}, 55^{\circ} \mathrm{C}$ for $30 \mathrm{~s}$ and $72{ }^{\circ} \mathrm{C}$ for $30 \mathrm{~s}$, and a final extension step at $72{ }^{\circ} \mathrm{C}$ for $10 \mathrm{~min}$.

Three replications of PCR amplification of each DNA sample were performed. Positive controls Escherichia coli and Fusarium verticillioides DNA were also included. All PCR events were conducted using Bio-Rad T-100 TM Thermal Cycler (Bio-Rad Laboratories, Inc., Hercules, CA, USA). Obtained PCR products for bacteria and fungi were subsequently verified by electrophoresis in $1.0 \%$ (wt/vol) and $1.5 \%$ (wt/vol) agarose gels, respectively, with SYBR ${ }^{\circledR}$ Safe (Invitrogen ${ }^{\mathrm{TM}}$, Carlsbad, CA, USA) pre-staining. Gel electrophoresis was ran with 0.5X TAE (Tris-acetate-EDTA) buffer at $100 \mathrm{~V}$ for 30 min using Mupid®-One System (Takara Bio USA, Inc.).

Table 1. PCR primers used in the amplification of bacterial 16S rDNA genes and fungal ITS regions from community DNA extracted from bulk and rhizosphere soils of mungbean

\begin{tabular}{|c|c|c|c|}
\hline Primer & Target & Sequence (5' to 3') & Reference \\
\hline 968 F-GC* & $\begin{array}{c}\text { Bacterial } \\
\text { 16S rDNA }\end{array}$ & $\begin{array}{c}\text { cgc ccg ggg cgc gcc ccg ggc ggg gcg ggg gca cgg } \\
\text { ggg gAA CGC GAA GAA CCT TAC }\end{array}$ & {$[31]$} \\
\hline R1378 & $\begin{array}{c}\text { Bacterial } \\
\text { 16S rDNA }\end{array}$ & CGG TGT GTA CAA GGC CCG GGA ACG & {$[32]$} \\
\hline ITS1F & Fungal ITS & CTT GGT CAT TTA GAG GAA GTA A & {$[33]$} \\
\hline ITS4 & Fungal ITS & TCC TCC GCT TAT TGA TAT GC & {$[34]$} \\
\hline ITS1F-GC* & Fungal ITS & $\begin{array}{c}\text { cgc ccg ccg cgc gcg gcg ggc ggg gcg ggg gca cgg } \\
\text { ggg gCT TGG TCA TTT AGA GGA AGT AA }\end{array}$ & {$[33]$} \\
\hline ITS2 & Fungal ITS & GCT GCG TTC TTC ATC GAT GC & {$[34]$} \\
\hline
\end{tabular}

*GC - 40 bases GC-rich nucleotide sequence (GC clamp) attached to 5' end of primer

Denaturing Gradient Gel Electrophoresis (DGGE). PCR products were separated by denaturing gradient gel electrophoresis (DGGE) using the DCode ${ }^{\mathrm{TM}}$ Universal Mutation Detection System (Bio-Rad Laboratories, Inc., Hercules, CA, USA). Twenty microliters DNA samples were added with $10 \mu \mathrm{L} 1 \mathrm{X}$ BlueJuice ${ }^{\mathrm{TM}}$ gel loading dye (Invitrogen $^{\mathrm{TM}}$ ) prior to use. For bacterial community analysis, PCR products were loaded onto $6 \%$ acrylamide/bisacrylamide $(37.5: 1)$ gel. A denaturing gradient of $50 \%$ to $70 \%$ was used for separation of PCR amplicons. The denaturant $(100 \%)$ contained $7 \mathrm{M}$ urea and $40 \%$ formamide. Electrophoresis was initially started at $100 \mathrm{~V}$ for $10 \mathrm{~min}$ and was then lowered to $60 \mathrm{~V}$ and ran for $17 \mathrm{~h}$ in a $0.5 \mathrm{X}$ TAE buffer at a constant temperature of $60^{\circ} \mathrm{C}$. Post-staining was done with Gel Red nucleic acid stain for at least $1 \mathrm{~h}$ in $0.5 \mathrm{X}$ TAE buffer with gentle shaking. Fungal community profiles were obtained following DGGE protocol as done for bacteria with modifications in gel specifications and running conditions. DNA samples were loaded onto $8 \%$ acrylamide/bisacrylamide gels with a linear gradient of $20 \%$ to $45 \%$. Additionally, the DGGE system was set at $50 \mathrm{~V}$ with a run time of $19 \mathrm{~h}$. All gels were imaged by UV transillumination using Bio-Rad Gel Doc ${ }^{\mathrm{TM}} \mathrm{XR}+$ system (Bio-Rad Laboratories, Inc., Hercules, CA, USA) and QuantityOne ${ }^{\mathrm{TM}}$ 1-D Gel Analysis Software. Prominent bands from the DGGE profiles were excised for sequence analysis.

Analysis of DGGE Profiles. DGGE profiles were examined through digital image analysis using a temporary BioNumerics 7.6 Software evaluation license from Applied Maths (Sint-MartensLatem, Belgium) following the manufacturer's instructions. Band detection was done by using the band-search algorithm and following background subtraction. Manual verification of undetected bands and removal of uncertain identifications were made for every gel image processing. Banding profiles were normalized using known markers as reference for inter-gel comparisons. Analyses of community fingerprints through clustering, principal components analysis (PCA), and calculation of diversity index for each gel track were accomplished with the software; permission to publish results had been received from Applied Maths. 
Clustering and Principal Components Analysis (PCA). Similarities among the banding patterns of the bacterial and fungal communities were analyzed using the Dice coefficient. The band-based coefficient was used along with a band matching tolerance of $1.0 \%$ to produce similarity matrices while the unweighted pair group method with arithmetic means (UPGMA) clustering algorithm was utilized to convert the matrices to dendrograms. Cophenetic correlations were employed to express consistency of dendrogram sub-clusters. Band-matching was done as prerequisite for construction of PCA plots.

Diversity Index. The structural diversity of each microbial community was analyzed through calculation of Shannon diversity index, H' [35] for every gel lane by means of a script provided in BioNumerics. Results were corroborated through manual computation using exported densitometric curves data of individual lanes. The Shannon diversity index $\left(\mathrm{H}_{\mathrm{S}}\right)$ was calculated as:

$$
H \mathrm{~s}=\sum_{i=1}^{n}-\frac{h i}{H} \ln \frac{h i}{H}
$$

where $n$ is the total number of bands in the profile, $h i$ is the intensity of the individual band, and $H$ is the total intensity of all bands in a profile. Average diversity indices per experimental variable were compared for differences. To determine which factors are significant sources of variation, Ftest using ANOVA at 5\% level of significance was used.

Sequence Analysis of Bacterial 16S rDNA and Fungal ITS Regions. PCR products from excised DNA bands were submitted to First BASE Laboratories (Selangor, Malaysia) for sample purification via gel extraction and double-pass sequencing. Consensus sequences were obtained for the forward and reverse sequences of each DNA sample through pairwise alignments using BioEdit Sequence Alignment Editor [36]. The nucleotide sequences from DGGE gels were compared with those from GenBank (https://www.ncbi.nlm.nih.gov/) using the BLASTN program [37]. Six partial $16 \mathrm{~S}$ rDNA and 22 ITS region sequences were assigned with nearest phylogenetic neighbors. Matches with $>90 \%$ similarity were aligned using ClustalW tool in the Molecular Evolutionary Genetics Analysis (MEGA) software 7.0.26 [38] to include more sequences for analysis. The alignment for each microbial group was then used to create bootstrapped $(n=1,000)$ neighbor joining trees. Methanobacterium oryzae and Corallochytrium limacisporum were used as outgroup for bacterial and fungal phylogenies, respectively.

\section{Results}

Soil Physico-chemical Properties. Soil physico-chemical properties (Table 2) measured from replicate field plots generally show no significant discrepancies supporting that there is minimal variation in the soil conditions between the adjacent replicate plots.

Table 2. Physico-chemical analyses of soil from Tranca, Bay, Laguna experiment site

\begin{tabular}{|c|c|c|c|c|c|c|}
\hline Plot & $\mathbf{p H}$ & $\begin{array}{c}\text { Moisture } \\
\text { content [\%] }\end{array}$ & $\begin{array}{c}\text { Organic } \\
\text { matter [\%] }\end{array}$ & $\begin{array}{c}\mathbf{K} \\
{[\mathbf{p p m}]}\end{array}$ & $\begin{array}{c}\mathbf{C a} \\
{[\mathbf{m e q} / \mathbf{1 0 0} \mathbf{g}]}\end{array}$ & $\begin{array}{c}\mathbf{M g} \\
{[\mathbf{m e q} / \mathbf{1 0 0} \mathbf{g}]}\end{array}$ \\
\hline $\mathrm{A}$ & 6.1 & 38.96 & 2.93 & 0.2953 & 5.000 & 0.789 \\
\hline $\mathrm{B}$ & 6.0 & 33.28 & 2.93 & 0.2752 & 4.878 & 1.014 \\
\hline
\end{tabular}

Analysis of Bacterial and Fungal DGGE Profiles. Molecular community fingerprints were prepared with three replications for each sampling event. Upon visual inspection, DGGE profiles showed relatively little variation among the replicates for each sampling times suggesting good reproducibility of the PCR amplification and DGGE procedures. The obtained community structures for bacteria and fungi were examined by providing general observations to more specific factors in the study (i.e. mungbean growth stage, soil sample and replicate plots) through clustering and PCA analyses. Comparison between the two microbial groups are presented accordingly. 
Community Shifts across Plant Growth. Initial inspection of bacterial DGGE profiles revealed relatively uniform patterns between flowering and physiological maturity samples (Figure 3A); the occurrence of dominant and dense array of faint bands among samples in both stages showed substantial resemblance.

In comparison with initial inspection, clustering provided an estimate of the similarities, and therefore, differences between community fingerprints. UPGMA analysis of combined data sets revealed that bacterial DGGE profiles were clustered based on plant growth stage (Figure 4A). DGGE profiles between flowering and physiological maturity stages had approximately $65 \%$ similarity. This observation indicates that there was a shift in bacterial community structure during plant growth. In addition to analysis of entire data sets, clustering and PCA for individual components of the study were also performed and are provided as supplementary data. A closer examination (Supplementary data 1) distinctly shows grouping between the two growth stages in bulk soil (Supplementary data 1C) and Plot A DGGE profiles (Supplementary data 1E). PCA of combined data sets for bacteria (Figure 5A) and of individual factors (Supplementary data 2C to 2F) corroborates this finding. Generally, two groupings among the PCA plots can be ascertained and this is attributed to different sampling times.

Fungal DGGE profiles were significantly different from those of bacteria; the occurrence of both dominant and faint bands were more variable among bulk and rhizosphere samples, between the two plant growth stages, and between replicates (Figure 3B). Additionally, there were more dominant populations particularly among physiological maturity community fingerprints. Clustering results (Figure 4B) provided estimation of how variable fungal DGGE profiles are over those of bacteria. Fungal DGGE profiles had a lower similarity of $\sim 50 \%$ and $60 \%$ among flowering and physiological maturity samples, respectively. Whereas, bacterial DGGE profiles (Figure 4A) had approximately $65 \%$ and $82 \%$ similarity for the two successive sampling events.

Change in the community fingerprints during plant development were also observed for fungi although the clustering apart of DGGE profiles between the growth stages were not as cohesive compared to that of bacteria; the collection of physiological maturity profiles were located between those of flowering stage samples. There was a 50-65\% similarity among profiles between the two growth stages. Dendrograms concentrated on soil environment (Supplementary data 3C and 3D) showed more distinguishable clustering of DGGE profiles between the growth stages. As for replicate plots $\mathrm{A}$ and $\mathrm{B}$ (Supplementary data $3 \mathrm{E}$ and $3 \mathrm{~F}$ ), the factor to which clustering can be attributed to was inconsistent. It appears that in Plot A, clustering was more influenced by type of soil sample while in Plot B, both growth stage and soil environment may be taken into account. PCA of total fungal (Figure 5B), and of bulk and rhizosphere soil (Supplementary data 4C and 4D) fingerprints show grouping of entries can be generally ascribed to growth stage although other subset plots do not project apparent groupings (Supplementary data 4E and 4F).

Genotype Effect. Analysis of DGGE profiles of rhizosphere microbial communities conferred the finding that the different mungbean genotypes based on drought tolerance do not appear to have apparent effects on soil bacterial community compositions. Community fingerprints of same genotypes from replicate plots did not cluster together (Supplementary data 1D). Higher similarities can be observed among different genotypes from the same plot in comparison to same genotypes from different plots. This was consistent in both flowering and physiological maturity stages. Furthermore, PCA did not exhibit close relatedness between entries of the same plant genotype. It remains that distribution was more affected by growth stage while grouping within DGGE profiles from the same sampling event was attributed to source plot (Supplementary data 2D). Observations from bacterial clustering were similar to that of results for fungi (Supplementary data 3D). PCA for fungal rhizosphere entries also did not display close distribution between entries of the same plant genotype (Supplementary data 4D). 


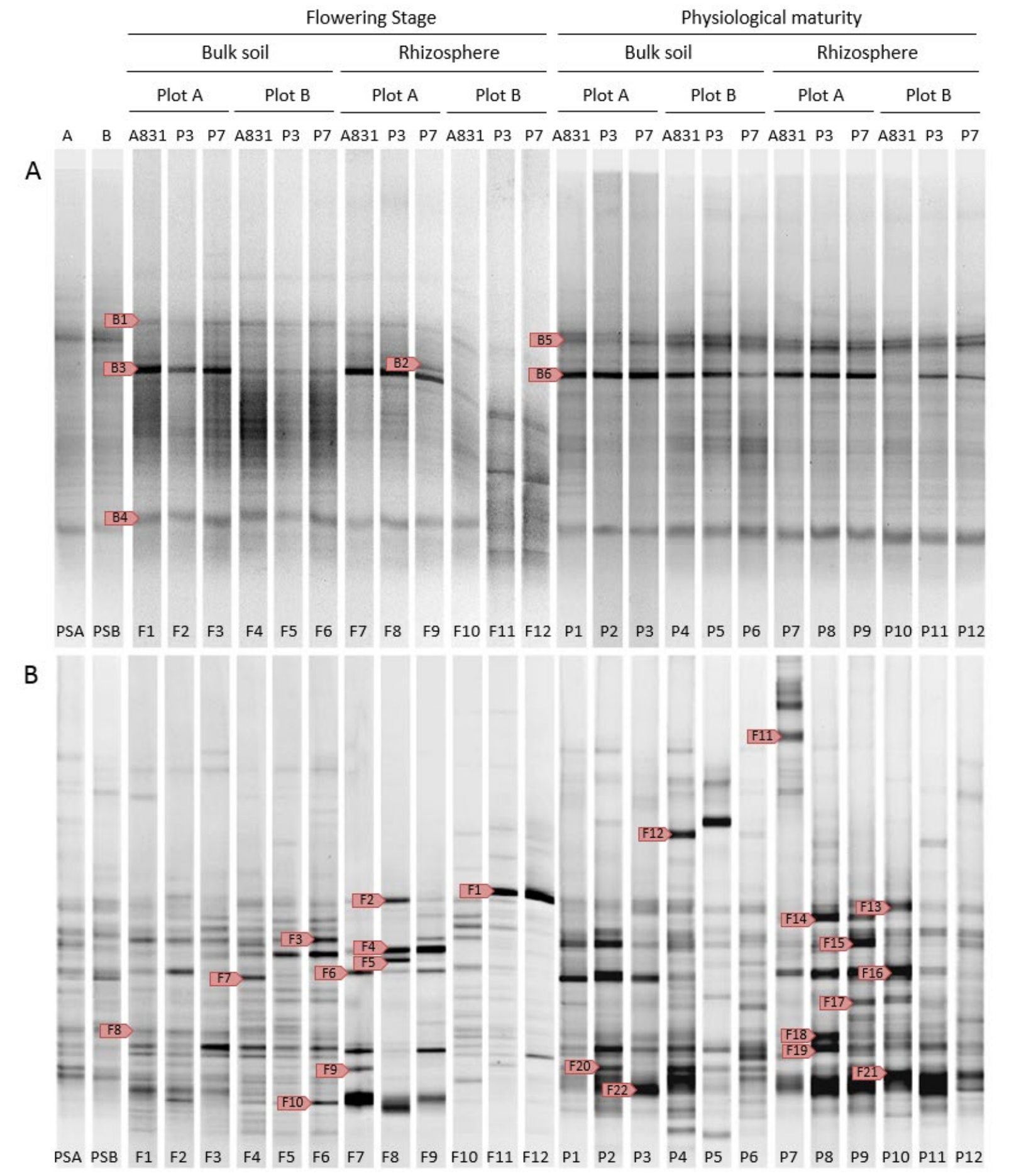

Figure 3. DGGE profiles of soil bacterial and fungal communities of mungbean. (A) DGGE band profiles of V6 to V8 hypervariable regions of bacterial 16S rDNA amplified from total genomic DNA extracted from bulk soil and rhizospheres of mungbean. The DGGE image represents a 50 to $70 \%$ denaturant gradient. (B) DGGE band profiles of fungal ITS1 region amplified from total genomic DNA extracted from bulk soil and rhizospheres of mungbean. The DGGE image represents a 20 to $45 \%$ denaturant gradient. Labeled bands denote samples sequenced for phylogenetic analysis while lane labels are reference for subsequent PCA analysis 


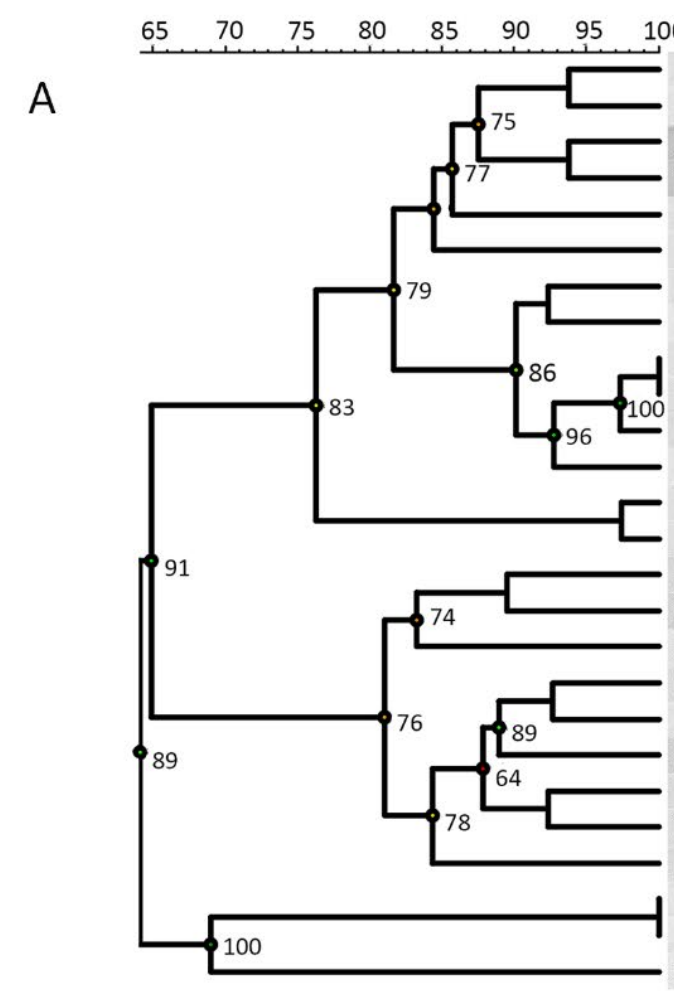

B-Bu-B-PM-A831
B-Bu-B-PM-P7
B-Bu-A-PM-P3
B-Bu-A-PM-P7
B-Bu-B-PM-P3
B-Bu-A-PM-A831
B-Rh-B-PM-A831
B-Rh-B-PM-P7
B-Rh-A-PM-P3
B-Rh-A-PM-P7
B-Rh-A-PM-A831
B-Rh-B-PM-P3
Pre-sowing (A-16S)
Pre-sowing (B-16S)
B-Rh-A-FL-A831
B-Rh-A-FL-P3
B-Rh-A-FL-P7
B-Bu-B-FL-A831
B-Bu-B-FL-P3
B-Bu-A-FL-A831
B-Bu-A-FL-P7
B-Bu-B-FL-P7
B-Bu-A-FL-P3
B-Rh-B-FL-P3
B-Rh-B-FL-P7
B-Rh-B-FL-A831
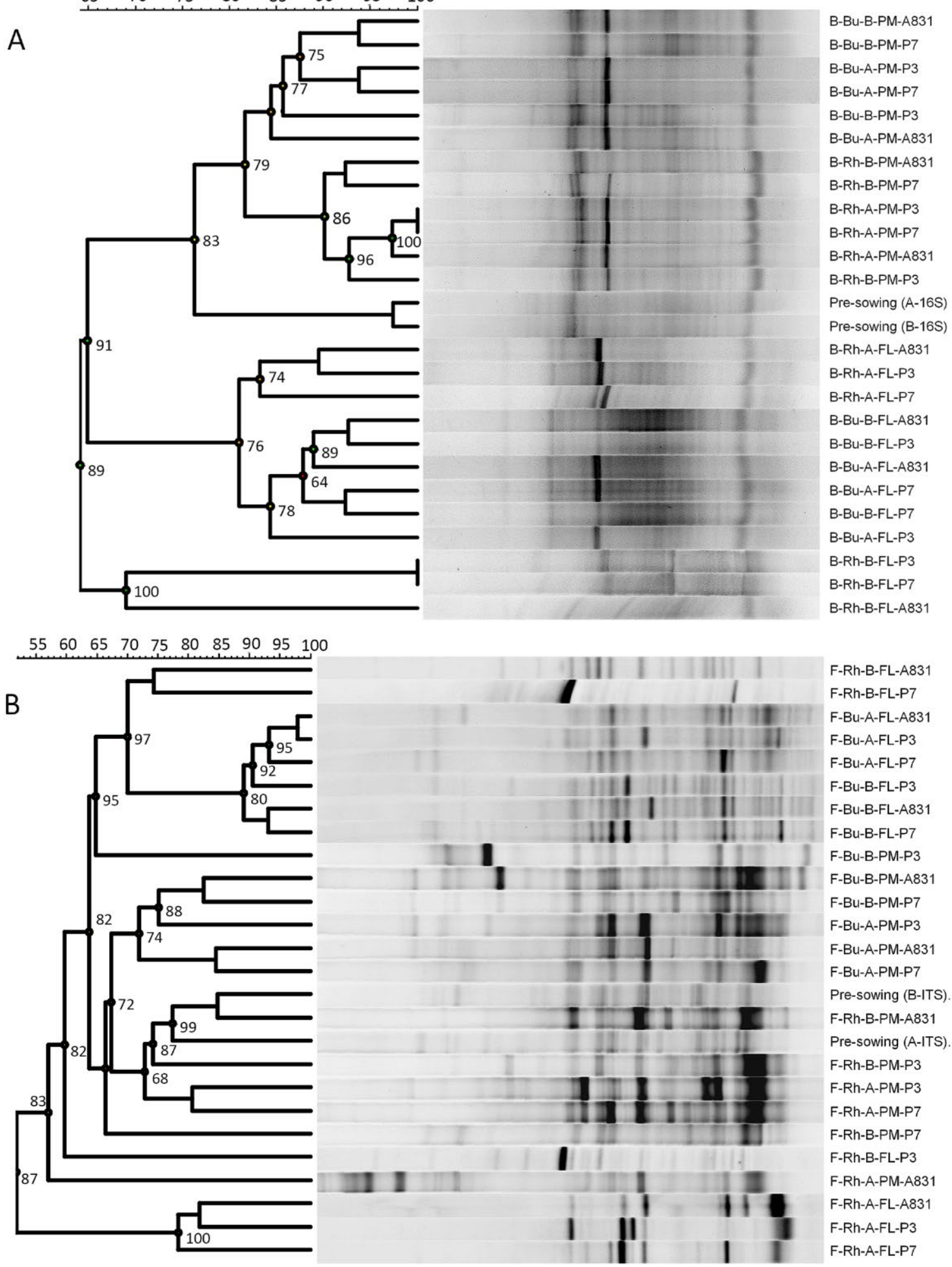

Figure 4. Clustering analyses for combined data sets of A) bacterial 16S rDNA and B) fungal ITS

DGGE profiles. Dendrograms represent the percent similarity of banding patterns based on unweighted pair group method with arithmethic mean (UPGMA) cluster analysis. Estimates of the reproducibility of each subcluster are represented by cophenetic correlations shown at the nodes of the dendrogram. The sample IDs are shown to the right of the DGGE image: B, bacteria; F, fungi; $\mathrm{Bu}$, bulk soil; Rh, rhizosphere; A, plot A; B, plot B; FL, flowering; PM, physiological maturity; A831, Acc A831; P3, Pag-asa 3; P7, Pag-asa 7 
A

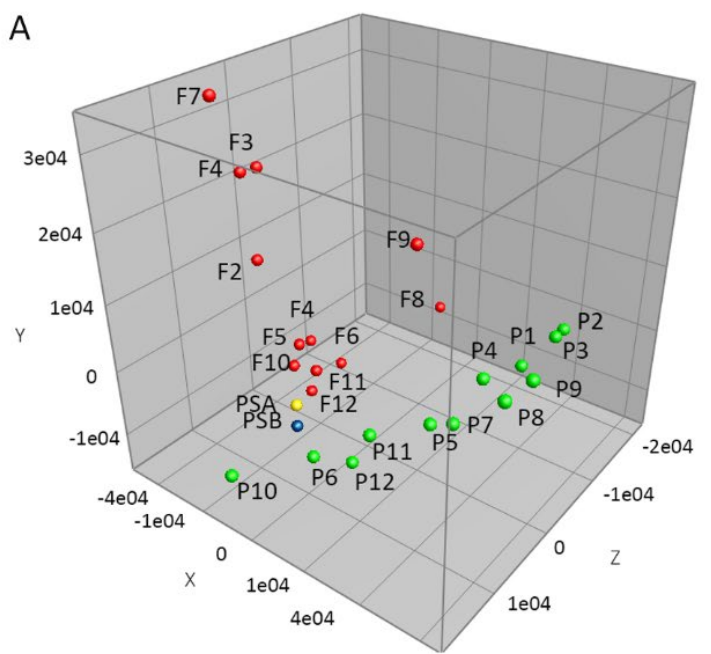

B

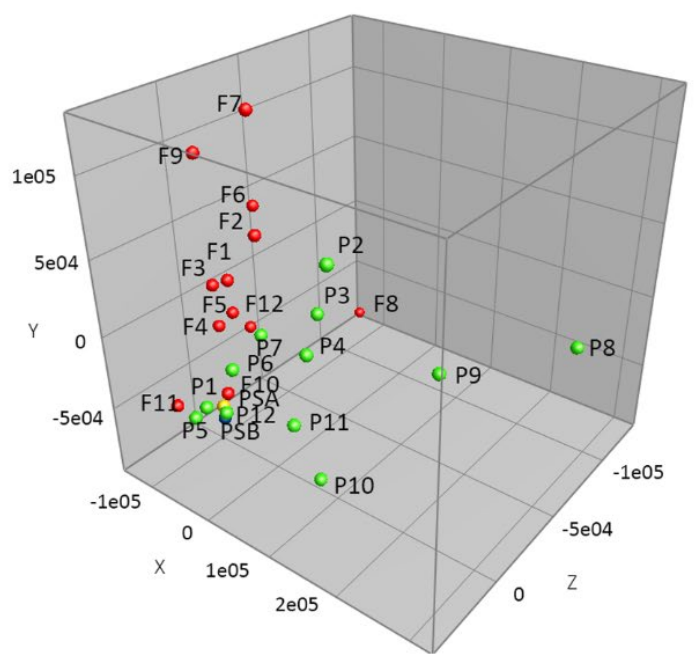

Figure 5. Principal component analysis (PCA) of all combined data sets for bacterial (A) and for fungal (B) PCR-DGGE profiles. Entries are labelled according to order in gel lanes based on Figure 3; flowering and physiological maturity samples are represented by $\mathrm{F}$ and $\mathrm{P}$, respectively; PSA and PSB are pre-sowing samples from the replicate plots

Rhizosphere Effect. Dendrogram for each growth stage showed that rhizosphere bacterial DGGE profiles tend to group separately from the corresponding bulk soil profiles (Supplementary data $1 \mathrm{~A}$ and $1 \mathrm{~B})$. Although flowering stage samples exhibited considerable range in variation (0 to $35 \%$ ) among rhizosphere profiles, cluster of bulk soil samples was intact with a minimum of $\sim 84 \%$ similarity. Physiological maturity profiles yielded complete separation between the two soil environments with a difference of almost 20\%. Additionally, PCA (Supplementary data 2A and 2B) expressed consistent findings. These observations suggest that there were distinguishable rhizosphere effects on the bacterial community compositions.

DGGE profiles among fungal rhizosphere communities did not distinctly cluster together in both growth stages (Supplementary data 3A and 3B). Nevertheless, bulk soil DGGE profiles were still observed to generally collect together. Differences between bulk soil and rhizosphere profiles ranged from $30-46 \%$ at flowering stage and $33-40 \%$ at physiological maturity. The grouping of fungal bulk soil communities was only clearly observed in subset PCA for flowering stage (Supplementary data 4A). Hence, it can be suggested that there is still some rhizosphere effect in fungal communities even though it is not as significant in comparison to that in bacterial communities.

These findings through multivariate analyses support that there were differences in microbial populations between independent soil and rhizosphere soil. However, these types of analysis provide more of the general picture of relatedness among soil microbial profiles. Typically, rhizosphere effect is recognized as enrichments of certain bacterial or fungal members in the root area compared to surrounding bulk soil. While it is possible to identify bands which are not present or faint in bulk soils but became present or prominent in corresponding rhizospheres, simple visual inspection is not sufficient and has potential biases. Correspondingly, rhizosphere effect was also explored in terms of microbial abundance by means of diversity index.

Bacterial and Fungal Diversity Analysis. No significant differences were observed between the H' computed for bulk and rhizosphere samples although results were generally slightly lower for the latter (Figure 6). This is true for nearly all mean diversity indices obtained among components of the study. The exemption for this survey was only observed when the sampling time was taken into consideration; there was a marginally higher $\mathrm{H}^{\prime}$ for both bacterial and fungal rhizosphere communities at physiological maturity (Figure 6C and 6D) in comparison to corresponding mean $\mathrm{H}^{\prime}$ in bulk soil. Moreover, the mean diversity of fungi in rhizosphere samples at physiological maturity (3.0003) was notably higher to that of flowering stage (2.0992). 
Mungbean genotypes (Supplementary data 5A and 5B) and replicate plots (Supplementary data 5C and 5D) also yielded unremarkable differences in diversity.

Between microbial groups, fungal diversity was observed to be fairly higher than bacteria in both bulk and rhizosphere soils. Mean diversity of fungi in rhizosphere soil was particularly higher than that of bacteria (2.3036) at physiological maturity. Higher standard deviation among mean H' of fungal rhizosphere communities gives the indication that fungal diversity surfaces as more dynamic than bacterial diversity.

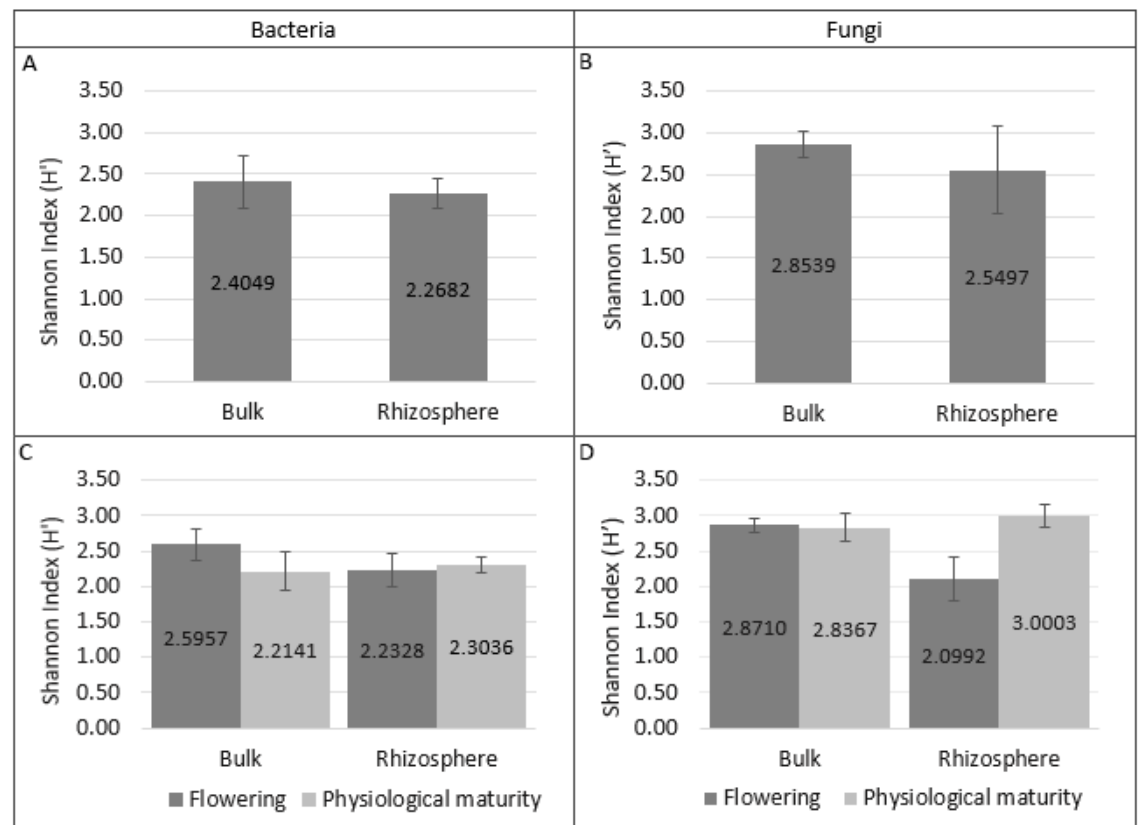

Figure 6. Mean Shannon diversity index of soil bacterial and fungal communities obtained for all combined data sets $(A, B)$, and for each mungbean growth stage $(C, D)$

Significant Contributors to Variation in Soil Microbial Diversity. Independently, mungbean growth stage and source plot were found to significantly contribute variations in bacterial diversity (Table 3). More so, the interaction between soil environment and growth stage also profoundly affects diversity $(\mathrm{P}<0.05)$. Mungbean growth stage and soil environment were also found to significantly affect fungal diversity, both as independent and interacting factors. Bacterial and fungal diversity in bulk soil lowers across plant development from flowering to physiological maturity, whereas it increases in rhizosphere (Figure 7).

Table 3. Significant contributors to variation in Shannon diversity of bacterial and fungal DGGE profiles determined through F-test using ANOVA

\begin{tabular}{|l|c|c|}
\hline \multirow{2}{*}{ Source } & \multicolumn{2}{c|}{ P-value $>$ F-value } \\
\cline { 2 - 3 } & Bacteria & Fungi \\
\hline Source plot & $0.0141^{*}$ & 0.3837 \\
\hline Mungbean genotype & 0.8118 & 0.5536 \\
\hline Soil environment & 0.2626 & $0.0378^{* *}$ \\
\hline Mungbean genotype x Soil environment & 0.6764 & 0.94 \\
\hline Growth stage & $0.0219^{*}$ & $0.0034^{* *}$ \\
\hline Mungbean genotype x Growth stage & 0.6816 & 0.7744 \\
\hline Soil environment x Growth stage & $0.0042^{* *}$ & $0.0023^{* *}$ \\
\hline Mungbean genotype x Soil environment x Growth stage & 0.5919 & 0.8319 \\
\hline
\end{tabular}

*Significant at $\mathrm{p}<0.05$.

$* *$ Highly significant at $\mathrm{p}<0.05$. 


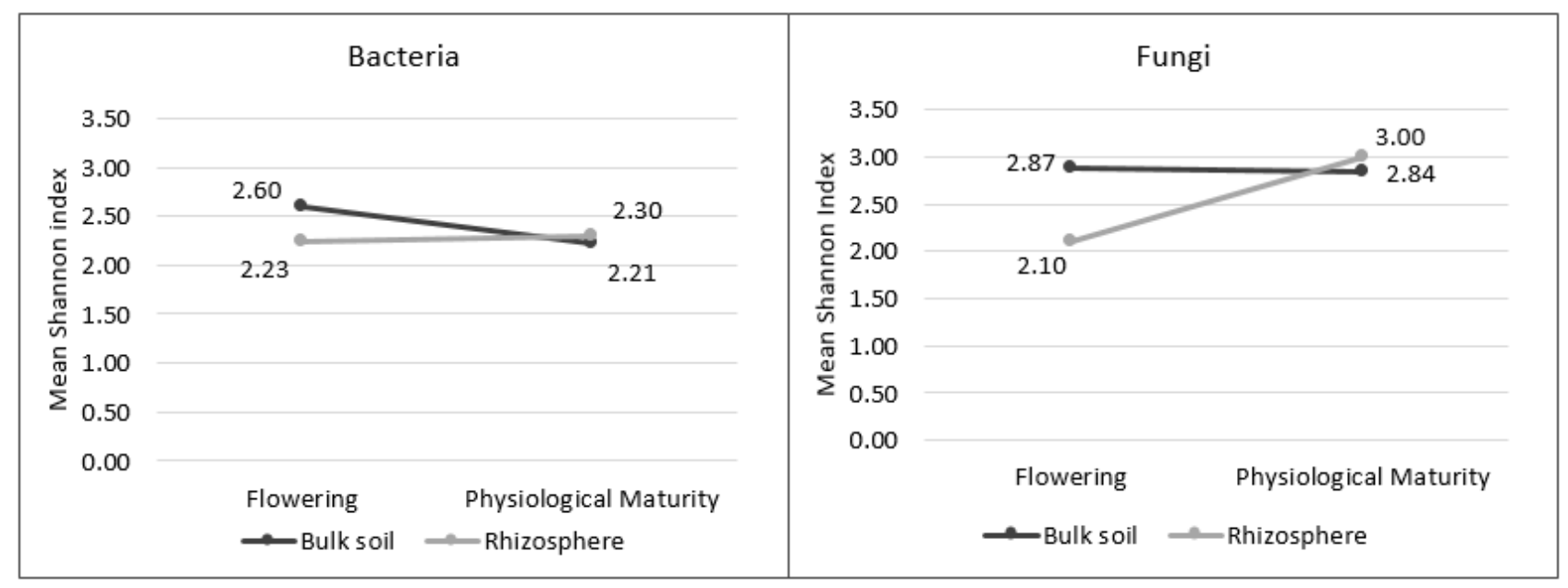

Figure 7. Interaction between mungbean growth stage and soil environment affecting mean Shannon diversity index of bacterial and fungal communities

Sequence Analysis of DGGE Bands. Tentative phylogenetic affiliations of six 16S rDNA gene and 22 ITS partial sequences are presented in Table 4. Bacterial DGGE band B1, which was discernible among bulk soil and rhizosphere samples at flowering stage but not at physiological maturity, showed $96 \%$ similarity to Bacillus megaterium. On the other hand, the prominent band (B6) at physiological maturity was recognized as a Bacillus sp. (73\%). Bands B3 and B6 from separate growth stage sampling were both found to be related to Arthrobacter sp. with $98 \%$ and $78 \%$ similarity, respectively. Additionally, these two bands were also observed to be dominant in both bulk and rhizosphere soils. Band B2 associated to Pseudomonas sp. (97\%) was found specific to Pag-asa 7 at flowering stage in all replicate DGGE gels. This observation is indicative of genotype effect; however, the lack of consistency in the two replicates make it inconclusive. Band B4, which was distinctly present from pre-sowing to physiological maturity, had the closest match to an uncultured Rhodocyclaceae clone (66\%).

Gram-positive bacteria belonging to the Bacilli and Actinobacteria groups were prominent populations in both bulk soil and rhizosphere of mungbean. As with a related study using potato, Bacillus megaterium was found to be dominant in both bulk soil and rhizospheres [39]. Bacillus species were also identified as dominant populations in the rhizospheres of chrysanthemum [20], barley [40], and of grass [41]. Arthrobacter species have also been reported to occur significantly in bulk soil of potato [39], and in the rhizosphere of chrysanthemum [20], Medicago sativa, Chenopodium album [42], and maize grown in tropical soil [43]. These findings add to the growing evidence that gram-positive bacteria are profoundly more dominant in the rhizosphere than previously supposed [39].

In comparison to DGGE profiles of bacteria, there are notably more dominant bands of varying electrophoretic mobility in the community fingerprints of fungi (Figure 3B). Half of the ITS sequences from flowering stage bands (F1 to F10) returned uncultured clones as closest match. Band F7 from bulk soil was 95\% similar to an uncultured Psathyrella clone. On the other hand, bands F4, F5, F9 and F10 from rhizosphere soil were assigned as Laccaria laccata var. pallidifolia (96\%), Aureobasidium sp. (98\%), uncultured Didymella clone (73\%) and uncultured Plectosphaerella clone (98\%), respectively. Several of the remaining bands from physiological maturity (F11 through F22) were also found to match uncultured clones with similarities ranging from 91 to $97 \%$. Distinct bands from the rhizosphere were recognized to be related to uncultured Athelia clone (F11, 98\%) and Hannaellla oryzae (F14, 96\%). Unfortunately, the presence of these bands in replicate plots were inconsistent and so it cannot be affirmed that these were dominant fungal populations in mungbean rhizosphere. Other phylogenetic affiliations that were associated to bands from rhizosphere and bulk soils include Fusarium delphinoides (F15, 96\%), Alternaria sp. (F16, 97\%), Peyronellaea glomerata (F18, 76\%), and the uncultured clones Didymella (F19, 97\%) and Plectrosphaerella (F22, 91\%). Among the recognized fungal identities, the ascomycetes 
Didymella (Order Pleosporales) and Plectosphaerella (Order Glomerellales) were recovered from both mungbean growth stages.

The relationship between sequences recovered from DGGE bands and from GenBank are presented in Figure 8. Although $97 \%$ is the typical minimum level of sequence similarity for comparative analysis of ITS regions [44] and of whole and partial 16S rRNA sequences [45], matches of at least $90 \%$ were still included for examining phylogeny since E-values were considerably high. It is notable that an uncultured eukaryote clone clustered with the outgroup Corallochytrium limacisporum, which has been previously used for the same purpose in AMF communities in legumes [46]. Corallochytrium is a marine protist that possesses molecular evidence of fungal signatures (i.e. alpha-aminoadipate reductase) and has been essential for understanding the evolutionary origin of animals and fungi. Moreover, the eukaryote clone (KY690339.1) from GenBank was detected from benthic sediments. It may be reckoned that the DNA amplified by ITS1f and ITS2 had portions of conserved fungal sequences but may potentially be a eukaryote other than fungi. Essentially, dominant members found in soil fungal communities of mungbean were found to belong to Ascomycota and Basidiomycota. Members from the two fungal divisions have also been found to be largely present in rhizospheres of maize [47] and in soybean where the ascomycete Plectosphaerella was also detected [48].

Table 4. Presumptive phylogenetic affiliations of bacteria and fungi present in bulk soil and mungbean rhizosphere recovered from DGGE bands

\begin{tabular}{|c|c|c|c|c|c|}
\hline $\begin{array}{l}\text { DGGE } \\
\text { Band }\end{array}$ & Closest relative $^{a}$ & E-value & $\begin{array}{c}\% \\
\text { Similarity } \\
\end{array}$ & Phylogenetic assignment & $\begin{array}{l}\text { GenBank } \\
\text { accession }\end{array}$ \\
\hline B1 & Bacillus megaterium strain MER_2 & 0 & $96 \%$ & Bacilli - Bacillales & KT719586.1 \\
\hline $\mathrm{B} 2$ & Uncultured Pseudomonas sp. clone 3.14 & 0 & $97 \%$ & Gammaproteobacteria - Pseudomonadales & DQ144425.1 \\
\hline $\mathrm{B}^{\mathrm{b}}$ & Arthrobacter sp. strain JWp9 & 0 & $98 \%$ & Actinobacteria - Micrococcales & KU597206.1 \\
\hline B4 & $\begin{array}{l}\text { Uncultured Rhodocyclaceae bacterium clone } \\
\text { F5OHPNU07IJUZF }\end{array}$ & $1.00 \mathrm{E}-48$ & $66 \%$ & Betaproteobacteria - Rhodocyclales & HQ086737.1 \\
\hline B5 & Bacillus sp. R21 & $1.00 \mathrm{E}-92$ & $73 \%$ & Bacilli - Bacillales & KJ499789.1 \\
\hline $\mathrm{B} 6^{\mathrm{b}}$ & Arthrobacter sp. strain JWp9 & $4.00 \mathrm{E}-105$ & $78 \%$ & Actinobacteria - Micrococcales & KU597206.1 \\
\hline F1 & Uncultured fungus clone 039A51958 & $8.00 \mathrm{E}-156$ & $95 \%$ & - & FJ386905.1 \\
\hline $\mathrm{F} 2$ & Uncultured fungus clone 7 & $7.00 \mathrm{E}-146$ & $99 \%$ & - & JX343327.1 \\
\hline F3 & Uncultured soil fungus clone $366 \_0090$ & $4.00 \mathrm{E}-133$ & $96 \%$ & - & DQ980588.1 \\
\hline F4 & Laccaria laccata var. pallidifolia voucher FF-52 & $4.00 \mathrm{E}-102$ & $96 \%$ & Basidiomycota - Agaricales & KF007942.1 \\
\hline F5 & Aureobasidium sp. 3 BRO-2013 & $7.00 \mathrm{E}-141$ & $98 \%$ & Ascomycota - Dothideales & KF367567.1 \\
\hline F6 & Uncultured fungus clone 036A27186 & $2.00 \mathrm{E}-96$ & $87 \%$ & - & JX381302.1 \\
\hline F7 & Uncultured Psathyrella clone B17 & $1.00 \mathrm{E}-154$ & $95 \%$ & Basidiomycota - Agaricales & JX135080.1 \\
\hline F8 & Uncultured fungus clone 036A19053 & $5.00 \mathrm{E}-107$ & $94 \%$ & - & JX373320.1 \\
\hline $\mathrm{F}^{\mathrm{c}}$ & Uncultured Didymella clone 191_K2_K8_K10_K11ov & $3.00 \mathrm{E}-28$ & $73 \%$ & Ascomycota - Pleosporales & KY430455.1 \\
\hline $\mathrm{F} 10^{\mathrm{d}}$ & Uncultured Plectosphaerella clone TVD_ITS1F-ITS4_66 & $8.00 \mathrm{E}-125$ & $98 \%$ & Ascomycota - Glomerellales & KF493966.1 \\
\hline F11 & Uncultured Athelia clone B10-1 & $5.00 \mathrm{E}-158$ & $98 \%$ & Basidiomycota - Corticiales & FM866386.1 \\
\hline F12 & Uncultured fungus clone 038A42871 & $2.00 \mathrm{E}-95$ & $97 \%$ & - & JX359671.1 \\
\hline F13 & Uncultured fungus clone ZSY201307-5 & $5.00 \mathrm{E}-117$ & $93 \%$ & - & KX515726.1 \\
\hline F14 & Hannaella oryzae & $5.00 \mathrm{E}-107$ & $96 \%$ & Basidiomycota - Tremellales & KU182505.1 \\
\hline F15 & Fusarium delphinoides isolate AmEc3 & $4.00 \mathrm{E}-123$ & $96 \%$ & Ascomycota - Hypocreales & KJ690090.1 \\
\hline F16 & Alternaria sp. ZJ9-6B & $3.00 \mathrm{E}-134$ & $97 \%$ & Ascomycota - Pleosporales & HM754629.1 \\
\hline F17 & Uncultured fungus clone Singleton_(216-1634_3172) & $6.00 \mathrm{E}-96$ & $91 \%$ & - & FJ780492.1 \\
\hline F18 & Peyronellaea glomerata strain D-1-6 & $1.00 \mathrm{E}-57$ & $76 \%$ & Ascomycota - Pleosporales & KT223332.1 \\
\hline F19 & Uncultured Didymella clone PPO 100-4 & $6.00 \mathrm{E}-121$ & $97 \%$ & Ascomycota - Pleosporales & KU245689.1 \\
\hline $\mathrm{F} 20$ & Uncultured eukaryote clone 163 & $2.00 \mathrm{E}-26$ & $93 \%$ & - & KY690339.1 \\
\hline $\mathrm{F} 21$ & Uncultured fungus clone Unisequence\#16-3745_0746 & $4.00 \mathrm{E}-113$ & $95 \%$ & - & GQ514351.1 \\
\hline $\mathrm{F} 22^{\mathrm{d}}$ & Uncultured Plectosphaerella clone TVD_ITS1F-ITS4_66 & $4.00 \mathrm{E}-103$ & $91 \%$ & Ascomycota - Glomerellales & KF493966.1 \\
\hline
\end{tabular}

a First hit result from GenBank by BLASTN program.

b,c,d Bands from separate sampling time (mungbean flowering and physiological maturity) returned similar phylogenetic affiliations. 
A

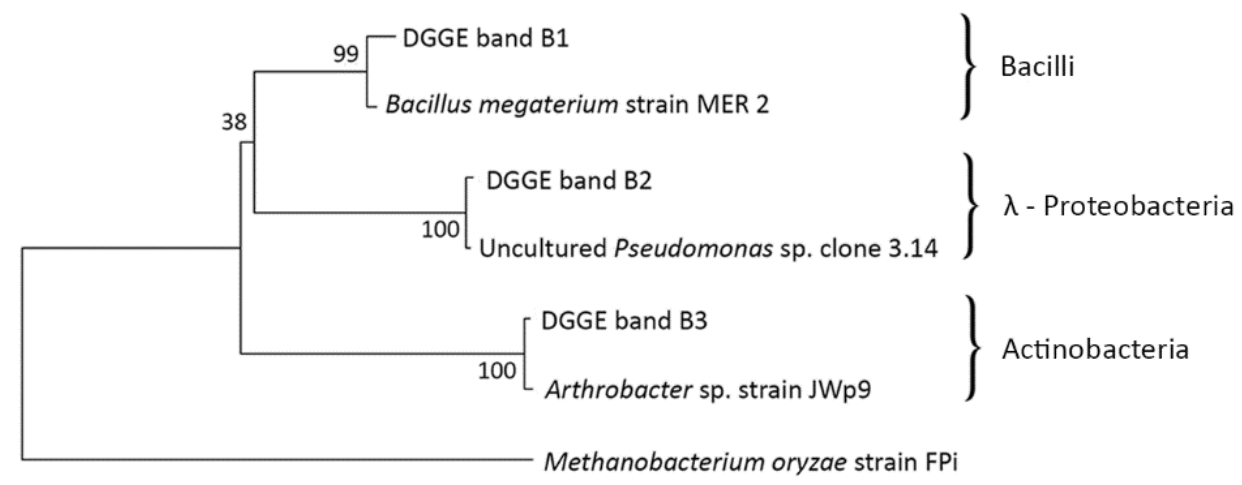

0.050

B

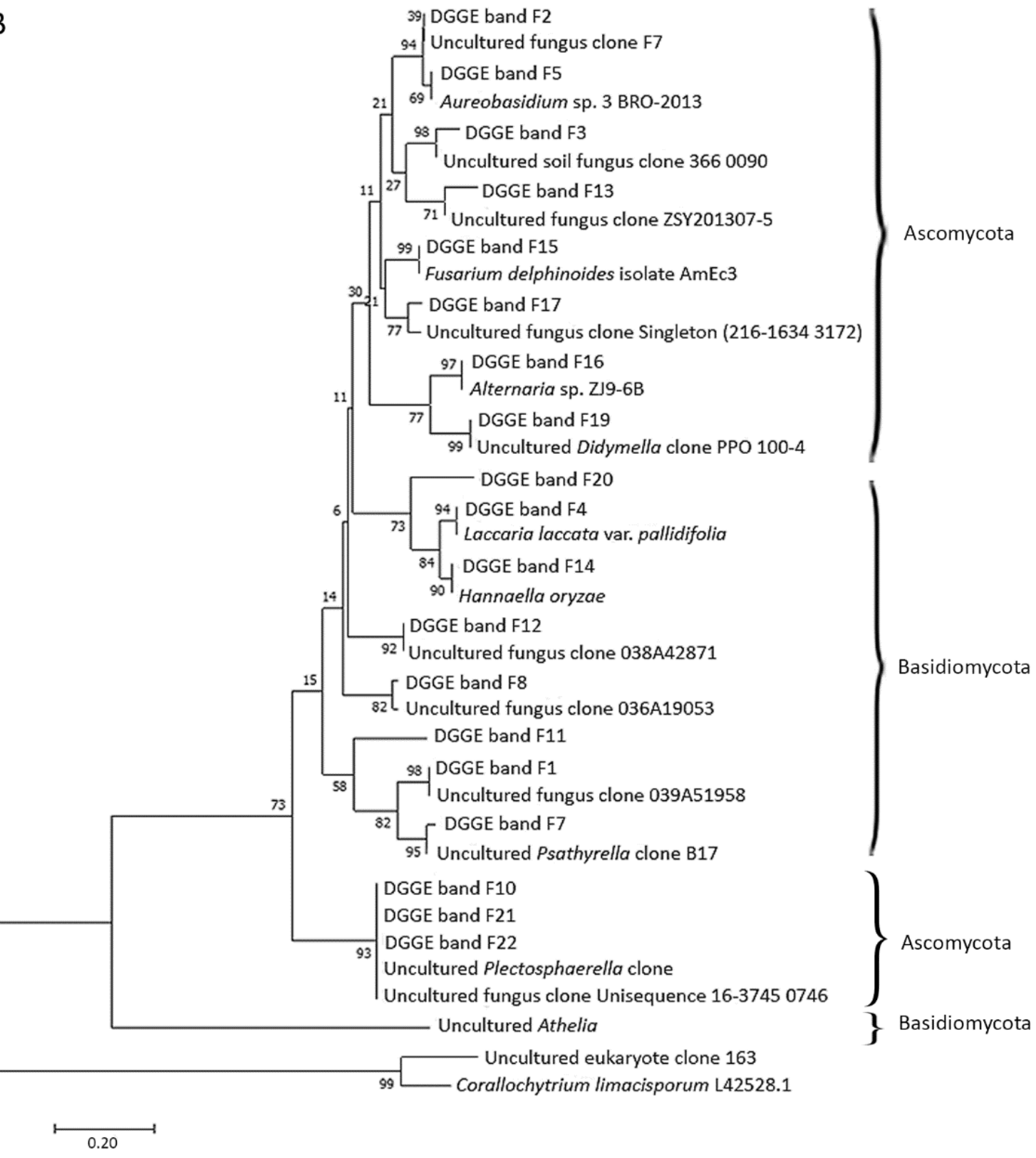

Figure 8. Neighbor-joining tree showing the phylogenetic relationship between partial sequences of 16S rDNA (A) and ITS regions (B) from DGGE bands, and retrieved sequences from GenBank database. The major groups of putative relatives are indicated along the right side of the figure.

Bootstrap values $(n=1,000)$ are indicated at the nodes 


\section{Discussion}

Bacterial Communities under Field Conditions. Integration of multivariate and diversity analyses revealed that community shifts occurred in rhizosphere bacterial populations during mungbean growth. Evident temporal shifts have been previously reported for all plant species in a field study using pea, wheat and sugar beet where bacterial rhizosphere communities were observed across five developmental stages [49]. Seasonal changes were also cited in rhizosphere bacterial communities of field-grown strawberry, oilseed rape, and potato plants [39]. In another legume, soybean, both pot and field experiments reported the same findings [50, 51]. While it was suggested that plant growth stage was secondary to soil type in shaping the bacterial communities in soybean rhizosphere [50], current analyses in mungbean rhizosphere only included the former, which is perceived emerging as the major factor. The shift in microbial communities across plant developmental stages may be attributed to changes in the quality and quantity of root exudates. Although these were not investigated in the present study, several publications have supported that alteration in root exudates occur during plant development [20,52-54], which in turn can influence microbial community structures.

It was expected that bulk soil communities would be relatively stable across plant growth stages but this was not the case. Bulk soil even exhibited greater difference in bacterial diversity between flowering and physiological maturity stages in comparison to rhizosphere. Inceoğlu et al. [55] similarly cited community changes over time in bulk soil in a two-field experiment using potato while Houlden et al. [49] reported otherwise. Soil microbial communities may be affected by a number of factors other than root exudates. Soil characteristics, environmental conditions and farming practices [56-58] may jointly contribute to their change through time. Considering the extent of each plot in the experiment $\left(289 \mathrm{~m}^{2}\right)$, soil sampling area was largely susceptible to various environmental conditions such as irradiation, temperature fluctuations, wind and moisture. Furthermore, it is noted that mungbean was grown during the transition from dry to rainy season wherein intermittent rains frequent the site.

It is recognized that root exudates differ not only in relation to plant growth stage but also to plant species and cultivar [59-62]. Study of Arabidopsis rhizosphere has demonstrated that the rate and mechanism at which bacterial community succession progresses is significantly dependent on plant genotype [63] whereas, it was suggested that a small portion of total rhizosphere bacteria were influenced by soybean genotype [50]. However, there was no apparent genotype effect observed among the three mungbean genotypes based on multivariate analyses. The differences in performance among the cultivars based on their tolerance to drought may considerably have been pronounced if these were subjected to the environmental stress. In turn, these phenotype variations under drought conditions may potentially influence rhizosphere microbiota to some degree. Such was the case in a recent study using four distinct rice genotypes for drought-induced changes in soil bacterial as well as fungal and archaeal communities. Santos-Medellin et al. [64] reported that rice genotype influences microbial composition in the rhizosphere; however, these effects were relatively minor and overall impacts of drought stress on microbial compositions were consistent for the different rice cultivars. Meanwhile, it is not firmly concluded that there was absolutely no genotype effect. For example, a band (B2) specific to Pag-asa 7 rhizosphere was detected at flowering stage (Figure 3A); while it may be an indication of selection by genotype, it wasn't considered as definite since it was only observed from plot A replicate. Furthermore, the technical limitation of DGGE of not being able to detect less abundant $(<1 \%)$ but potentially important members of the community may have hindered better resolution of results. Ultimately, it is suggested that the influence of mungbean genotype on bacterial community composition deserves a more intensive examination to obtain better resolution on the matter.

The rhizosphere is indeed an area of complex interactions between plant roots and soil that affects microorganism-driven activities [11]. The different compositions of root exudates are expected to elicit different responses from bacteria, and therefore, there is selection of rhizosphere communities [52]. Accordingly, the rhizosphere effect describes the phenomenon that the biomass and activity of microorganisms are enhanced as a result of root-released materials in comparison 
with bulk soil [65]. Gomes et al. [47] had also described it as a reduced diversity and an increased relative abundance of a few populations.

Rhizosphere effect was detected in the present study; however, the degree as to how significant this effect was cannot be stated but at most was estimated by percentage difference between bulk and rhizosphere fingerprints. Diversity analyses demonstrated that there was a significant relationship between growth stage and soil environment. Bulk soil bacterial diversity decreased as mungbean matured whereas rhizobacterial diversity exhibited a slight increase. Even though the rhizosphere had lower diversity than bulk soil at flowering stage and for total data sets, it does not lead to the inference that there was no rhizosphere effect. Inceoğlu et al. [55] reported that the influence of roots on bacterial populations is still deemed present in such instances although the effect may be small or transient. Furthermore, the presence of bands that were detected to be weak at bulk soil but became intense at rhizosphere samples, and vice versa, provides another indication of root influence. Previously mentioned field experiments by Smalla et al. [39] and Inceoğlu et al. [55] also reported rhizosphere effects.

Fungal Communities under Field Conditions. Soil fungal communities also underwent changes, albeit not as distinct as that of bacteria, during mungbean growth. Genotype effect was also not discernible which may be ascribed to lack of manifestation of differences of the cultivars based on drought tolerance under natural field conditions. As for rhizosphere effect, it was also detected for fungal communities although less apparent based on multivariate analyses. Fundamentally, plant growth and soil environment significantly affects fungal diversity. These observations were parallel with findings of both pot and field experiments using three soybean genotypes regarding growth stage and genotype effect [48], and a field experiment using two maize cultivars with respect to the three factors investigated [47].

Fungal communities exhibited greater increase in relative abundance in rhizosphere from flowering to physiological maturity compared to rhizobacteria. In contrast, Wang et al. [48] suggested more complex fungal community in soybean early reproductive stages than that in later stages due to decreasing trend in DGGE band count from early to late growth stages. Taking combined data sets into account, lower rhizosphere fungal diversity compared to bulk soil was also observed similar to bacteria. Finally, bulk soil and rhizosphere fungal communities were found to have high heterogeneity between replicates, and appears to be more dynamic in comparison to bacterial communities. It is considered that under field conditions, the experimental plots were exposed to intermittent rain and dry intervals from near flowering to physiological maturity stage. This link may be supported by a microcosm study by Kaisermann et al. [66], which tested the impact of small water content fluctuations in non-extreme conditions on bacterial and fungal community composition. They reported that there was no robust change in bacterial community composition, molecular microbial biomass, and fungal:bacterial ratio associated with soil water content change. In contrast, water fluctuation induced a strong change in the fungal community structure and rapidly alternated between states corresponding to the high and low levels of soil moisture content. Referring to previous publications, the authors offered that the rapid shift could be explained by rapid hyphal turnover and the ability of some taxa to grow even in drying periods. As such, high plasticity is conferred to fungal communities. Moreover, the changes in community composition did not affect metabolic performance as supported by the idea that the latter is maintained by functional redundancy in non-extreme moisture conditions [66].

For the present study, the identification of significant microbial groups associated with mungbean-grown soil is at its most rudimentary level. The dense frequency of bands in bacterial and fungal DGGE profiles, as well as the erratic patterns observed in the latter, illustrate the complexity of highly diverse microbial communities in bulk soil and rhizosphere of mungbean. There is a need to further evaluate the less distinguished but nonetheless, potentially important microorganisms. As such, the subsequent use of group-specific primers to gain better resolution among members of the community may be used to address this concern. The use of polyphasic approaches ranging from traditional cultivation techniques to modern metagenomics would also be complementary for understanding not just the structure but also functions of the soil microbial 
communities. Ultimately, the study ventures toward the prospect of understanding and exploiting the functions of these microbial communities in correlation to their recognized importance in sustainable agriculture, particularly in the midst of climate change [67,68].

\section{Conclusions}

The research provided an overview of mungbean bacterial and fungal community structures and their dynamics as they coexist under agricultural field conditions through PCR-DGGE and multivariate analyses. With the exclusion of the factor of soil type, plant growth stage was found consistent to be the primary driver of community shifts in both microbial groups. The influence of rhizosphere environment was less pronounced in fungal communities whereas genotype effect was not detected within the conditions of the study. Fungal communities were revealed to be more diverse and heterogenous; yet, more prone to changes under the interplay of environmental factors. The observed community structures can be complemented with further studies on the functional diversity of the soil microorganisms. Elucidating the physiological interactions between the plant and microbial groups and even feasibly identifying potentially plant-beneficial bacterial or fungal members are valuable approaches to the employment of these soil microorganisms for improved crop productivity and for addressing agricultural sustainability.

\section{Conflict of Interest}

The authors declare no conflict of interests regarding the publication of this research.

\section{Acknowledgments}

This research was supported by the DOST-ASTHRDP Scholarship grant, DOST-PCAARRD Thesis Assistance Program and DOST project "Development of Mungbean Varieties for Drought and Partial Shade Tolerance. Field and molecular laboratory activities were accommodated by the Plant Physiology Laboratory, Institute of Plant Breeding, Los Baños, Laguna. DGGE equipment was provided by the Animal Biotechnology Laboratory, College of Agriculture, UPLB. We also thank the two anonymous reviewers for their constructive comments and suggestions on the previous version of this manuscript. 


\section{Supplementary Data}

A. Mungbean flowering

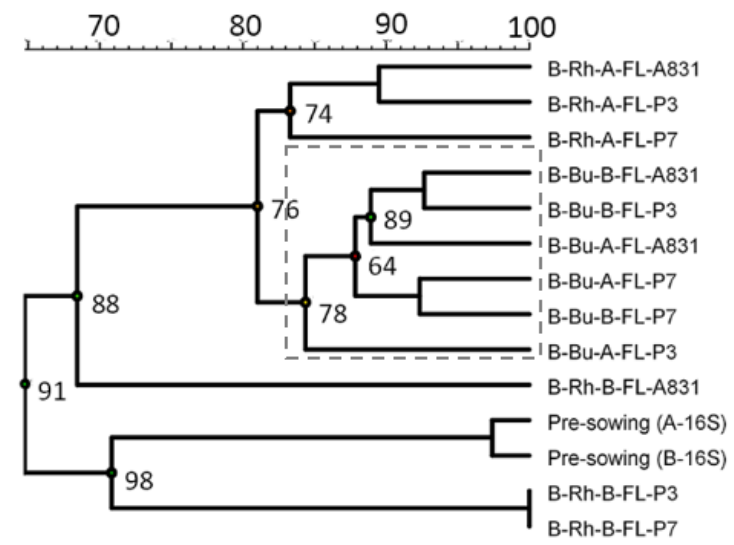

C. Bulk soil

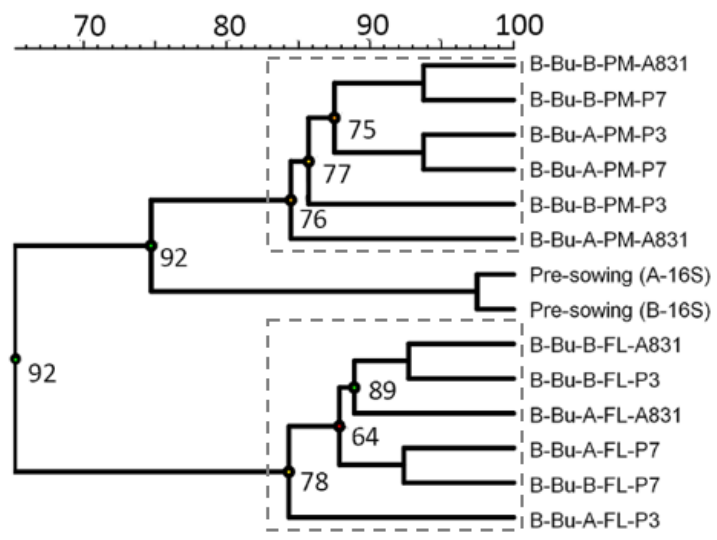

E. Plot A

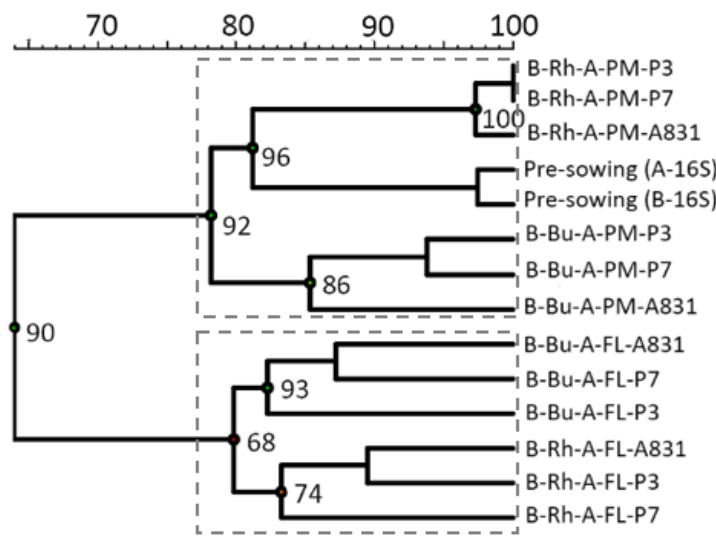

B. Mungbean physiological maturity

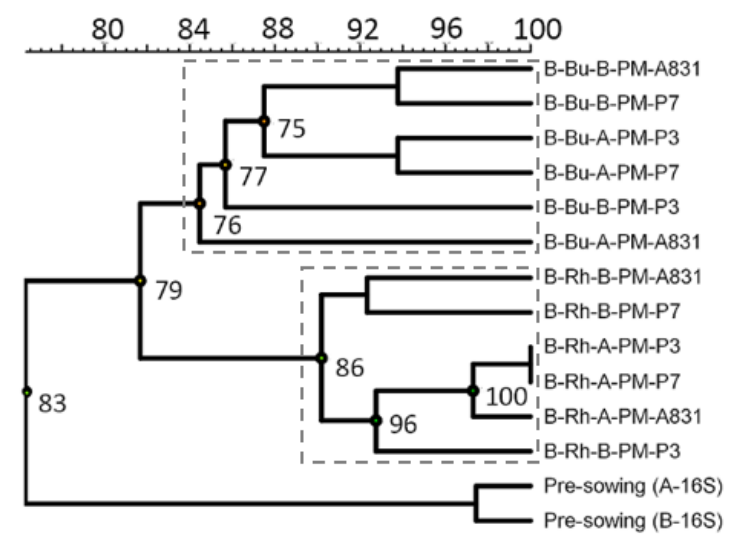

D. Rhizosphere soil

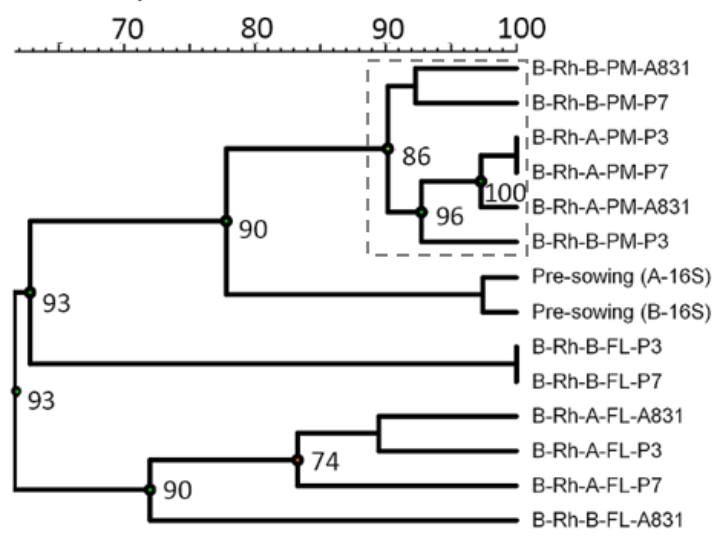

\section{F. Plot B}

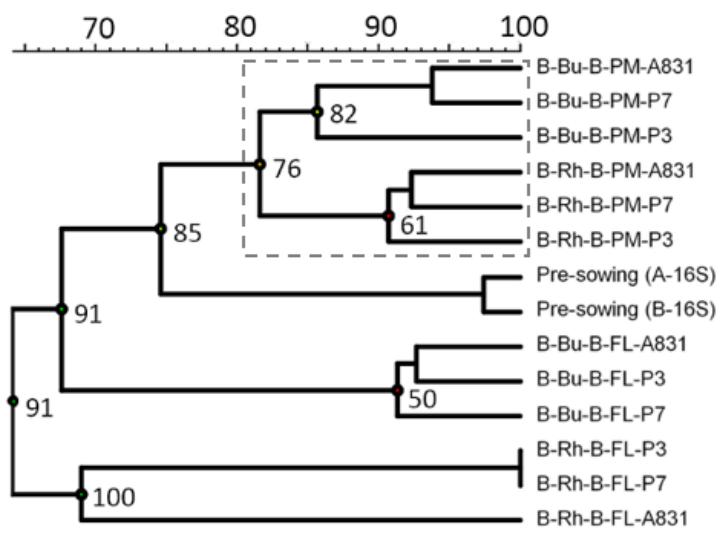

Supplementary data 1. Clustering analyses of bacterial 16S rDNA DGGE profiles based on individual factors of soil sampling time, soil environment and source plot. Scale denotes percent similarity of banding patterns and numbers at the nodes of dendrograms represent cophenetic 
A. Mungbean flowering

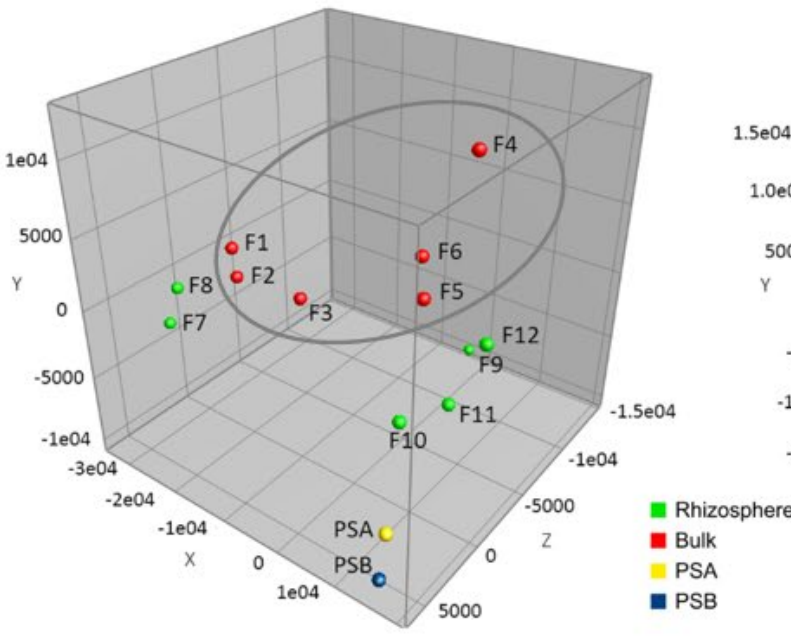

B. Mungbean physiological maturity

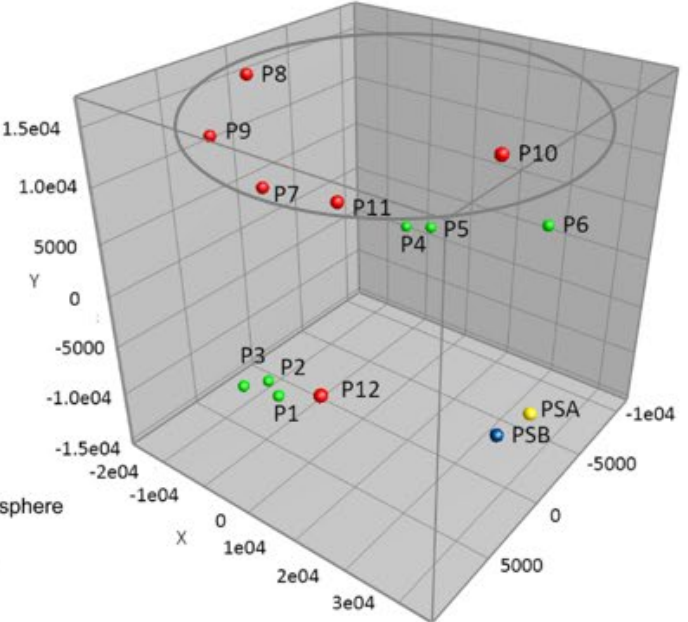

D. Rhizosphere soil
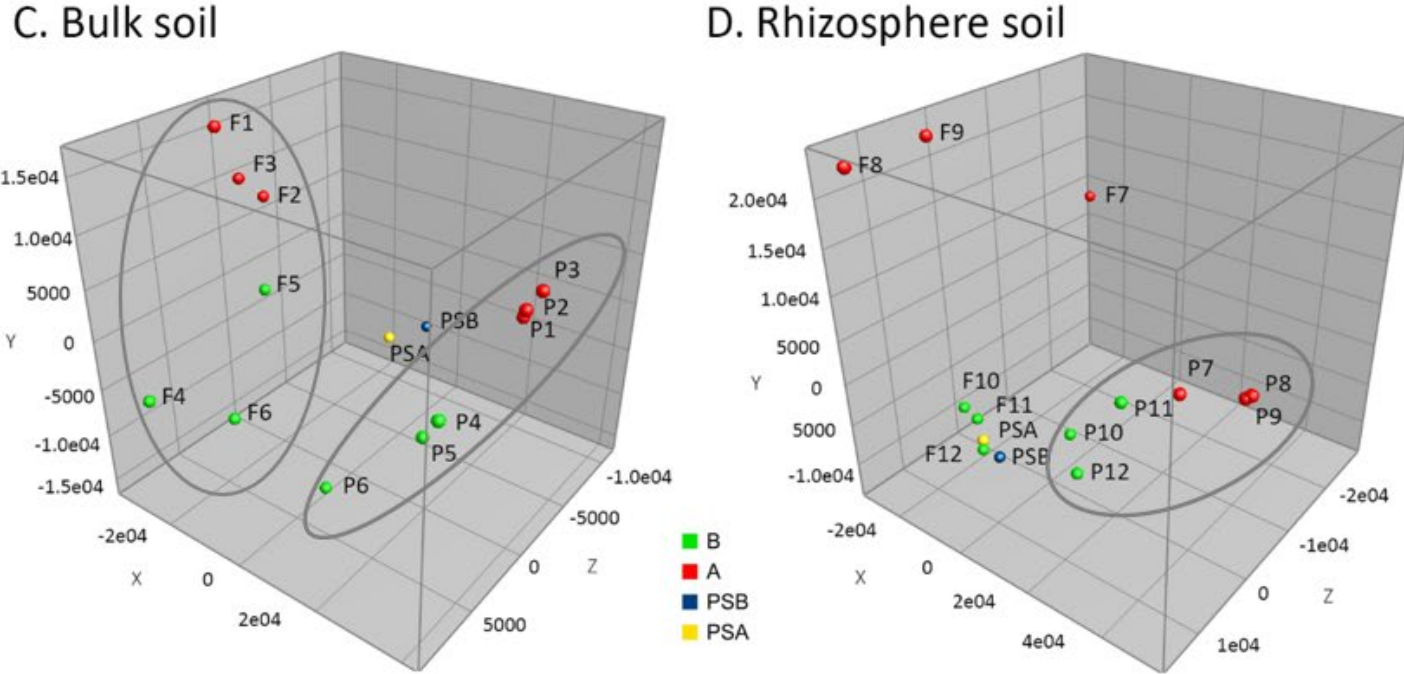

E. Plot A

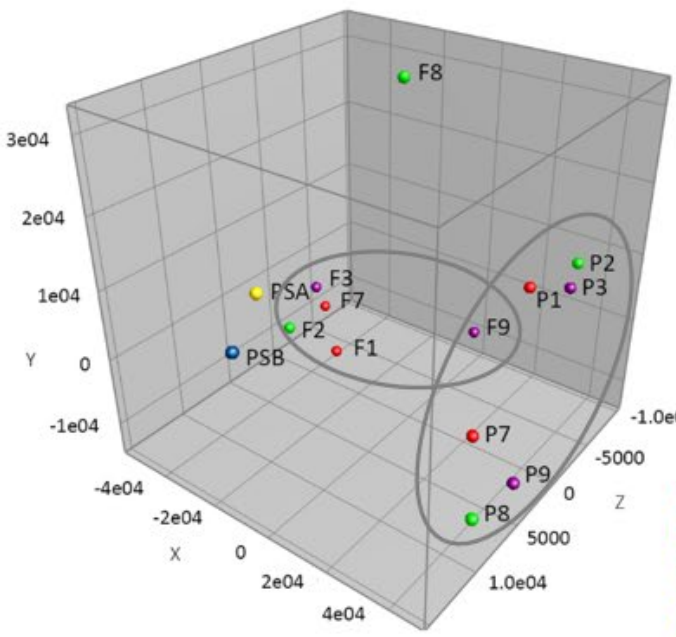

F. Plot B

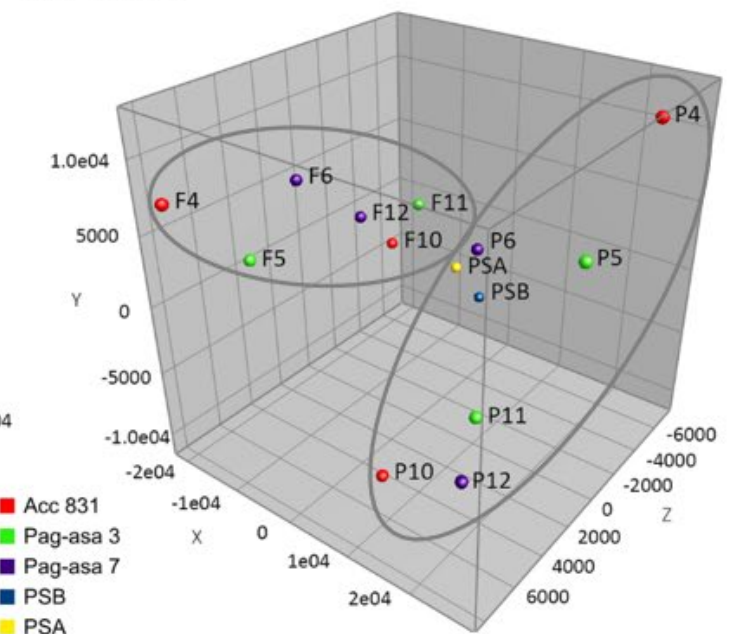

Supplementary data 2. Principal components analysis (PCA) of bacterial 16S community PCRDGGE profiles according to plant growth stage (A,B), soil environment (C,D) and source plot (E,F) 
A. Mungbean flowering

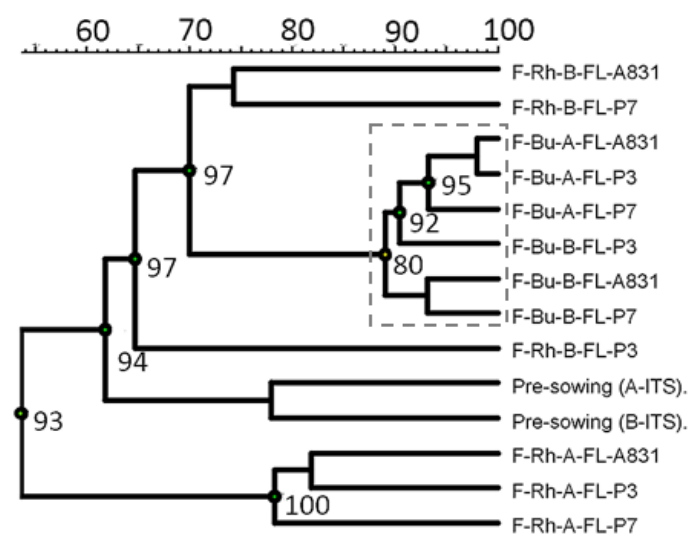

C. Bulk soil

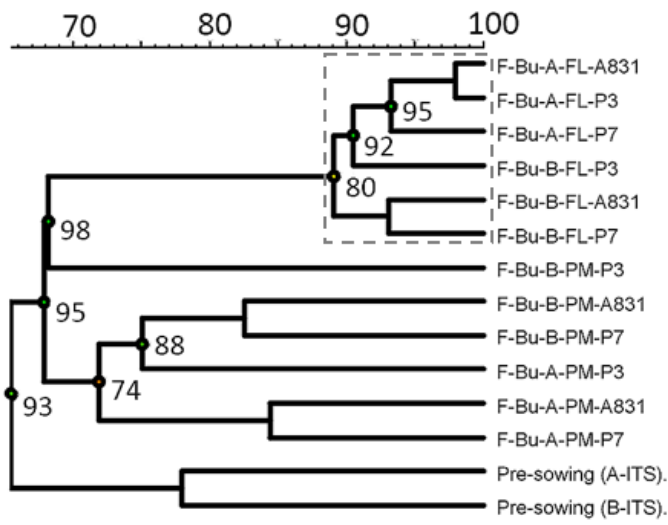

E. Plot A

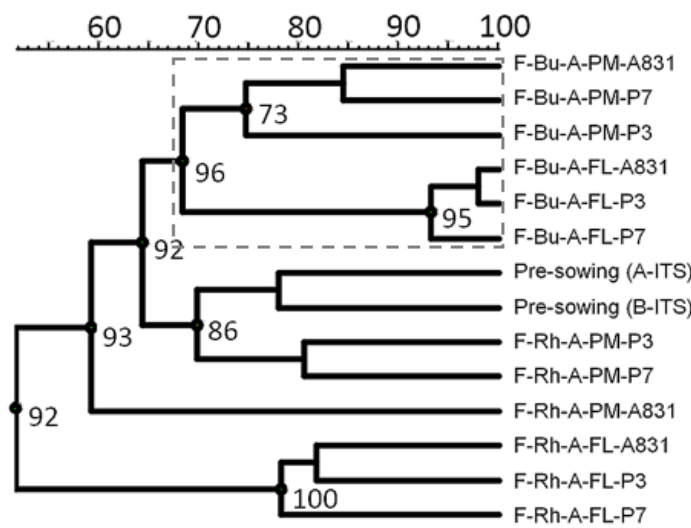

B. Mungbean physiological maturity

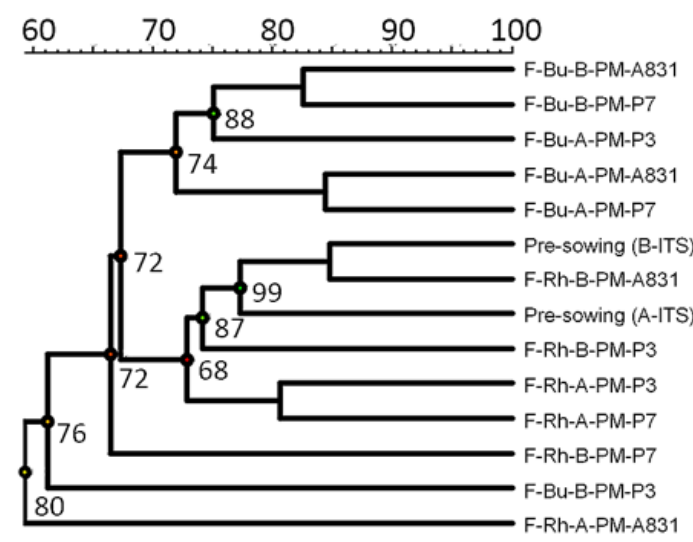

D. Rhizosphere soil

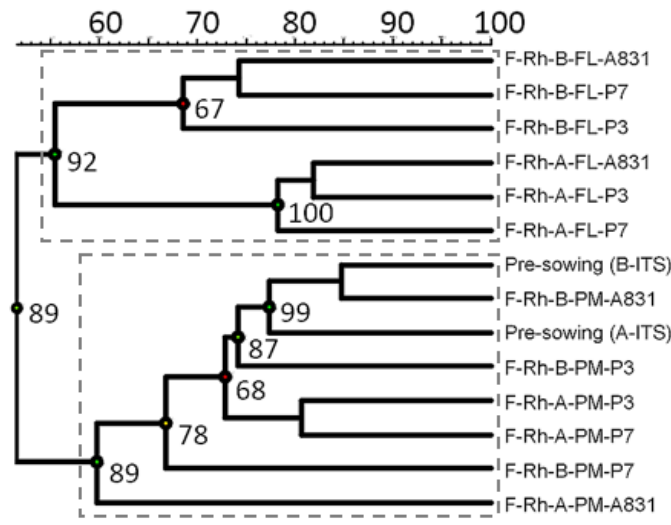

\section{F. Plot B}

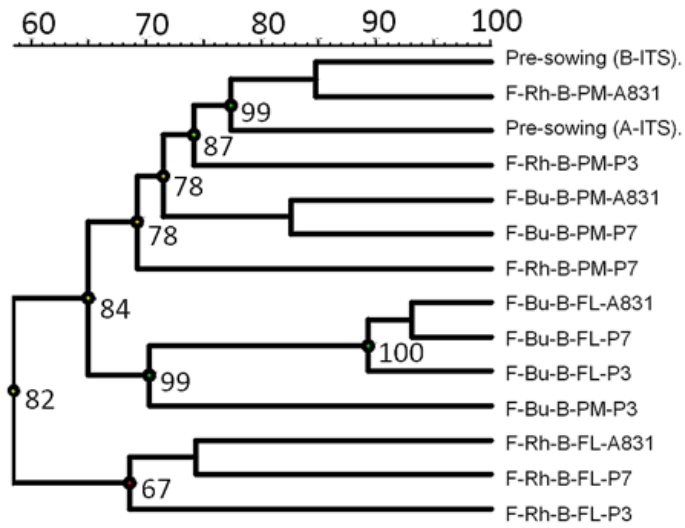

Supplementary data 3. Clustering analyses of fungal ITS DGGE profiles based on individual factors of soil sampling time, soil environment and source plot. Scale denotes percent similarity of banding patterns and numbers at the nodes of dendrograms represent cophenetic correlations 

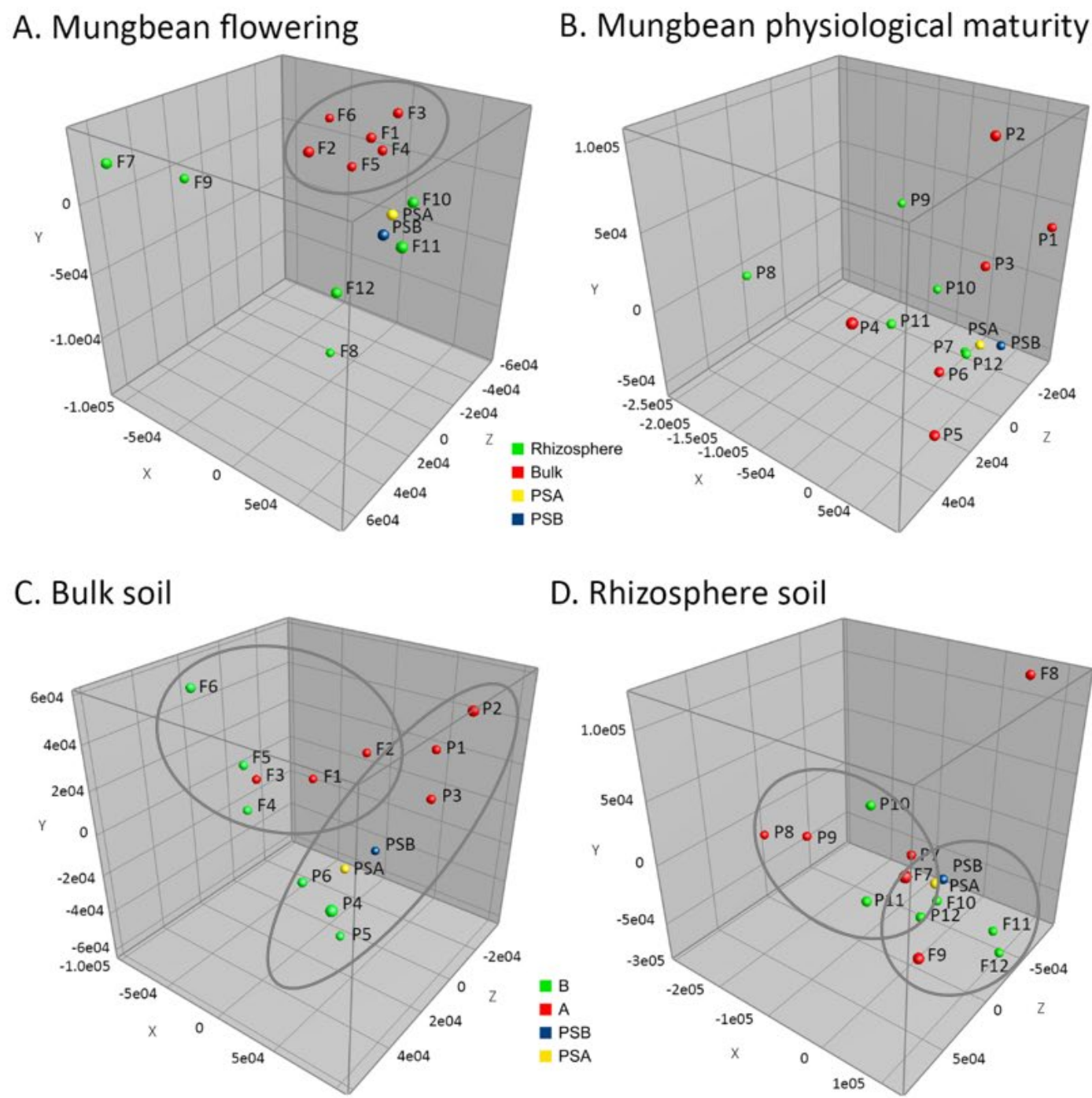

D. Rhizosphere soil

\section{E. Plot A}

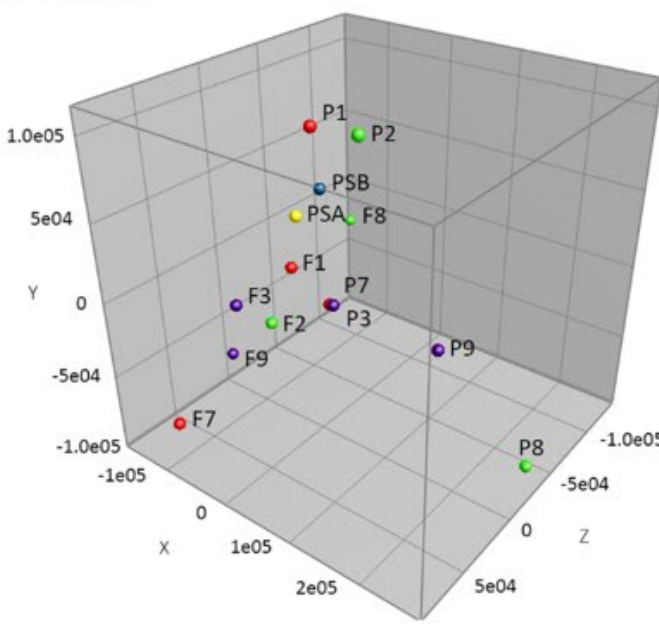

F. Plot B

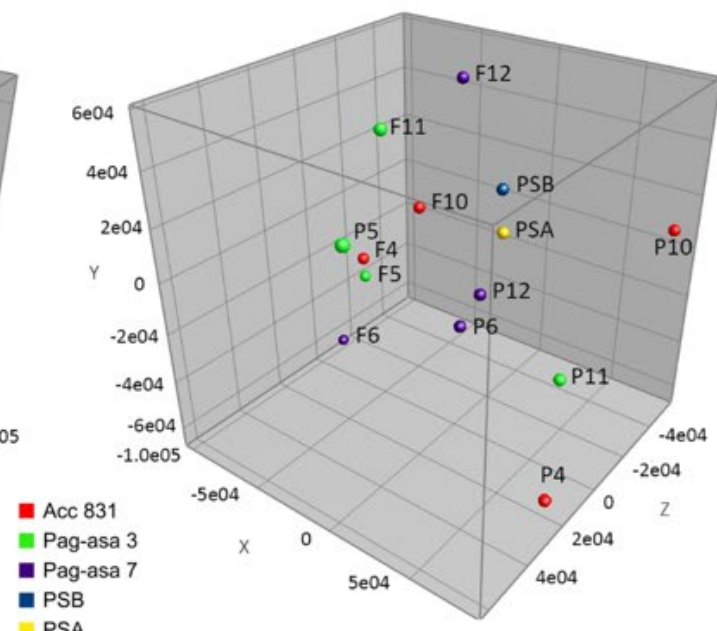

Supplementary data 4. Principal components analysis (PCA) of fungal ITS1 community PCRDGGE profiles according to plant growth stage (A, B), soil environment (C,D) and source plot $(\mathrm{E}, \mathrm{F})$ 


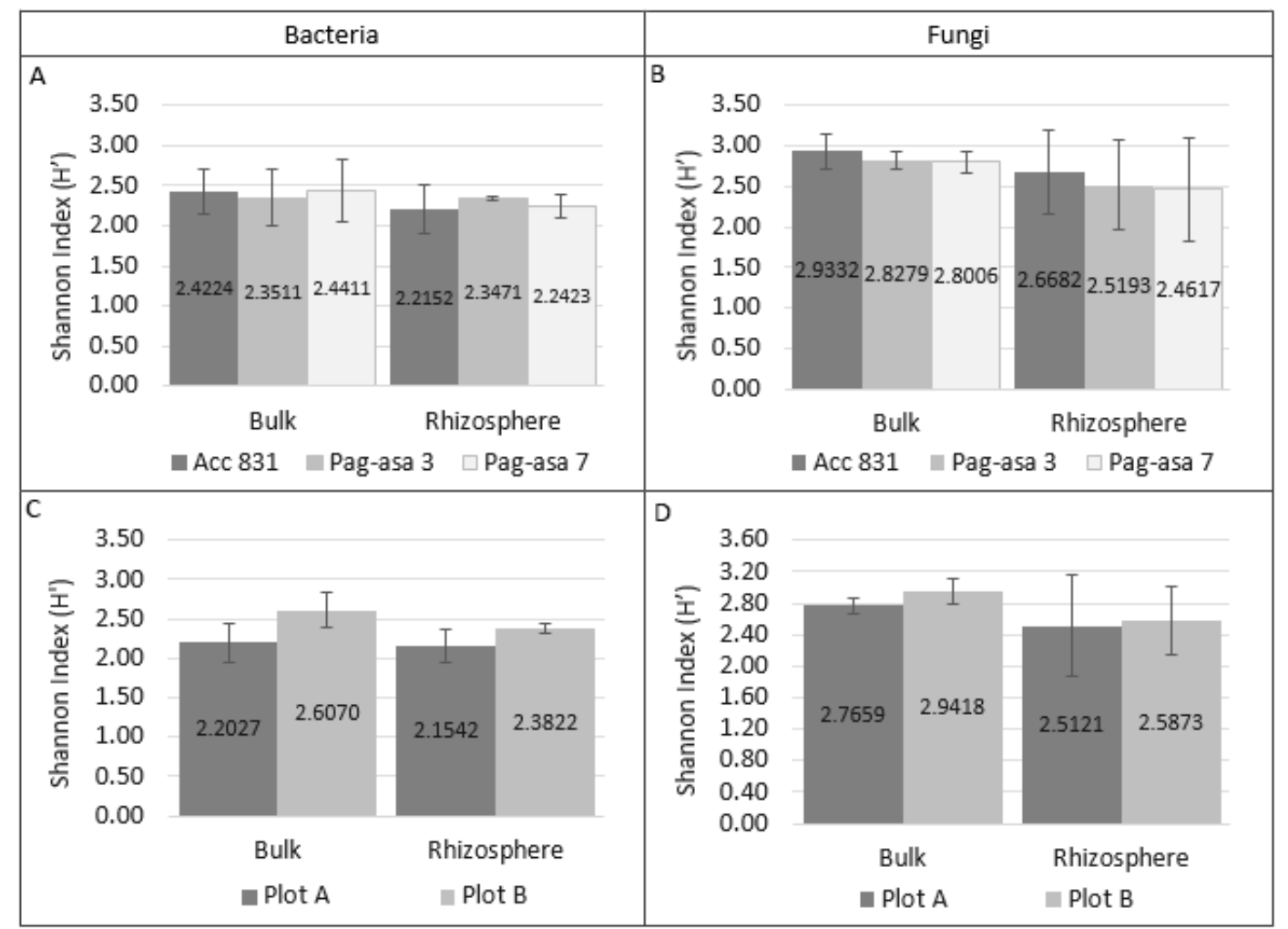

Supplementary data 5. Mean Shannon diversity index of soil bacterial and fungal communities obtained for mungbean genotype (A,B) and source plot $(C, D)$

\section{References}

[1] C. Emmerling et al., Functional diversity of soil organisms - a review of recent research activities in Germany, Journal of Plant Nutrition and Soil Science. 165 (2002) 408-420.

[2] J. Nesme et al., Back to the future of soil metagenomics, Frontiers in Microbiology. 7 (2016) $1-5$.

[3] J.C. Hunter-Cevera, The value of microbial diversity, Current Opinion in Microbiology. 1(3) (1998) 278-285.

[4] M.C. Rillig, D.L. Mummey, Mycorrhizas and soil structure, New Phytologist. 171 (2006) 4153.

[5] M. Van der Heijden, R. Bardgett, N. Van Straalen, The unseen majority: soil microbes as drivers of plant diversity and productivity in terrestrial ecosystems, Ecology Letters. 11(3) (2008) 296-310.

[6] P.A. Maron et al., High microbial diversity promotes soil ecosystem functioning, Applied and Environmental Microbiology. 84(9) (2018) doi: 10.1128/AEM.02738-17.

[7] S.M. Hermans et al., Bacteria as emerging indicators of soil condition, Applied and Environmental Microbiology. 83(1) (2016) doi: 10.1128/AEM.02826-16.

[8] L. Avidano et al., Characterization of soil health in an Italian polluted site by using microorganisms as bioindicators, Applied Soil Ecology. 30 (2005) 21-33.

[9] P. Trivedi et al., Response of soil properties and microbial communities to agriculture: implications for primary productivity and soil health indicators, Frontiers in Plant Science. 7(990) (2016) doi: 10.3389/fpls.2016.00990.

[10] R.L. Berendsen, C.M. Pieterse, P.A. Bakker, The rhizosphere microbiome and plant health, Trends in Plant Science. 17(8) (2012) 478-486. 
[11] G. Berg, K. Smalla, Plant species and soil type cooperatively shape the structure and function of microbial communities in the rhizosphere, FEMS Microbiology Ecology. 68(1) (2009) 113.

[12] L. Innes, P.J. Hobbs, R.D. Bardgett, The impacts of individual plant species on rhizosphere microbial communities in soils of different fertility, Biology and Fertility of Soils. 40(1) (2004) 7-13.

[13] P. Garbeva, J.D. van Elsas, J.A. van Veen, Rhizosphere microbial community and its response to plant species and soil history, Plant and Soil. 302(1/2) (2008) 19-32.

[14] P.H. Graham, C.P. Vance, Legumes: importance and constraints to greater use - update on legume utilization, Plant Physiology. 131(3) (2003) 872-877.

[15] AVRDC (Asian Vegetable Research and Development Center), Counting on beans: mungbean improvement in Asia, UK Aid from the Department of International Development. [Online].

Available: https://assets.publishing.service.gov.uk/media/57a08b1ced915d3cfd000b38/DFID_impact_ca se_study_Mungbean_FINAL_1_.pdf.

[16] N.C. Altoveros, T.H. Borromeo, The state of the plant genetic resources for food and agriculture of the Philippines - a country report (1997-2006), Department of Agriculture, Bureau of Plant Industry, 2007.

[17] R.F. Denison, E.T. Kiers, Life histories of symbiotic rhizobia and mycorrhizal fungi, Current Biology. 21(18) (2011) R775-R785.

[18] J. Lalande, R. Villemur, L. Deschênes, A new framework to accurately quantify soil bacterial community diversity from DGGE, Microbial Ecology. 66(3) (2013) 647-658.

[19] C. Carrigg et al., DNA extraction method affects microbial community profiles from soils and sediment, Applied Microbiology and Biotechnology. 77(4) (2007) 955-964.

[20] B.M. Duineveld et al., Analysis of bacterial communities in the rhizosphere of chrysanthemum via denaturing gradient gel electrophoresis of PCR-amplified 16S rRNA as well as DNA fragments coding for 16S rRNA, Applied and Environmental Microbiology. 67(1) (2001) 172-178.

[21] C.H. Nakatsu, Soil microbial community analysis using denaturing gradient gel electrophoresis, Soil Science Society of America Journal. 71(2) (2007) 562-571.

[22] G. Muyzer, E.C. de Waal, A.G. Uitterlinden, Profiling of complex microbial populations by denaturing gradient gel electrophoresis analysis of polymerase chain reaction-amplified genes coding for 16S rRNA, Applied and Environmental Microbiology. 59(3) (1993) 695-700.

[23] C.H. Nakatsu, V. Torsvik, L. Øvreås, Soil community analysis using DGGE of 16S rDNA polymerase chain reaction products, Soil Science Society of America Journal. 64(4) (2000) 1382-1388.

[24] J.K. Brons, J.D. van Elsas, Analysis of bacterial communities in soil by use of denaturing gradient gel electrophoresis and clone libraries as influenced by different reverse primers, Applied and Environmental Microbiology. 74(9) (2008) 2712-2727.

[25] I.C. Anderson, C.D. Campbell, J.I. Prosser, Diversity of fungi in organic soils under a moorland - Scots pine (Pinus sylvestris L.) gradient, Environmental Microbiology. 5(11) (2003) 1121-1132.

[26] R.R. Artz et al., Changes in fungal community composition in response to vegetational succession during the natural regeneration of cutover peatlands, Microbial Ecology, 54(3) (2007) 508-522. 
[27] Google, Experiment site location at Tranca, Bay, Laguna, Philippines [Online]. Available: https://www.google.com/maps/place/14\%C2\%B008'22.4\%22N+121\%C2\%B015'33.7\%22E/

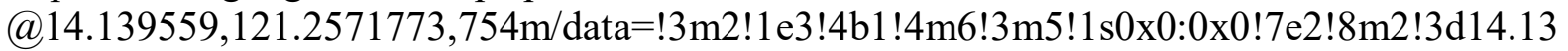
95586!4d121.259366.

[28] D.A. Del Rosario et al., Adaptation of vegetable legumes to drought stress, in C.G. Kuo (Ed.), Adaptation of Food Crops to Temperature and Water Stress: Proceedings of an International Symposium, Asian Vegetable Research and Development Center, 1992, pp. 360-371.

[29] F.I. Fatima et al., Microbial DNA extraction from soil by different methods and its PCR amplification, Biochemical and Cellular Archives. 11(1) (2011) 85-90.

[30] V. Valášková, P. Baldrian, Denaturing gradient gel electrophoresis as a fingerprinting method for the analysis of soil microbial communities, Plant, Soil and Environment. 55(10) (2009) 413-423.

[31] A. Felske et al., Direct ribosome isolation from soil to extract bacterial rRNA for community analysis, Applied and Environmental Microbiology. 62(11) (1996) 4162-4167.

[32] H. Heuer, K. Smalla, Application of denaturing gradient gel electrophoresis (DGGE) and temperature gradient gel electrophoresis (TGGE) for studying soil microbial communities, in: J.D. Van Elsas, E.M.H. Wellington, J.T. Trevors (Eds.), Modern Soil Microbiology, Marcel Dekker, New York, 1997, pp. 353-373.

[33] M. Gardes, T.D. Bruns, ITS primers with enhanced specificity for basidiomycetes application to the identification of mycorrhizae and rusts, Molecular Ecology. 2(2) (1993) $113-118$.

[34] T.J. White et al., Amplification and direct sequencing of fungal ribosomal RNA genes for phylogenetics, in: M.A. Innis, D.H. Gelfand, J.J. Sninsky, T.J. White (Eds.), PCR Protocols: A Guide to Methods and Applications, Academic Press, New York, 1990, pp. 315-322.

[35] C.L. Shannon, W. Weaver, The mathematical theory of communication, University of Illinois Press, Urbana, Illinois, 1963.

[36] T.A. Hall, BioEdit: a user-friendly biological sequence alignment editor and analysis program for Windows 95/98/NT, Oxford University Press, Nucleic Acids Symposium Series. 41 (1999) 95-98.

[37] S.F. Altschul et al., Gapped blast and psi-blast: a new generation of protein database search programs, Nucleic Acids Research. 25(17) (1997) 3389-3402.

[38] S. Kumar, G. Stecher, K. Tamura, MEGA7: Molecular Evolutionary Genetics Analysis version 7.0 for bigger datasets, Molecular Biology and Evolution. 33(7) (2016) 1870-1874.

[39] K. Smalla et al., Bulk and rhizosphere soil bacterial communities studied by denaturing gradient gel electrophoresis: plant-dependent enrichment and seasonal shifts revealed, Applied and Environmental Microbiology. 67(10) (2001) 4742-4751.

[40] B. Normander and J.I. Prosser, Bacterial origin and community composition in the barley phytosphere as a function of habitat and presowing conditions, Applied and Environmental Microbiology. 66(10) (2000) 4372-4377.

[41] A. Felske et al., Phylogeny of the main bacterial 16S rRNA sequences in Drentse A grassland soils (The Netherlands), Applied and Environmental Microbiology. 64(3) (1998) 871-879.

[42] F. Schwieger, C.C. Tebbe, Effect of field inoculation with Sinorhizobium meliloti L33 on the composition of bacterial communities in rhizospheres of a target plant (Medicago sativa) and a non-target plant (Chenopodium album) - linking of 16S rRNA gene-based single-strand conformation polymorphism community profiles to the diversity of cultivated bacteria, Applied and Environmental Microbiology. 66(8) (2000) 3556-3565. 
[43] N.C.M. Gomes et al., Bacterial diversity of the rhizosphere of maize (Zea mays) grown in tropical soil studied by temperature gradient gel electrophoresis, Plant and Soil. 232 (2001) 167-180.

[44] H.E. O'Brien et al., Fungal community analysis by large-scale sequencing of environmental samples, Applied and Environmental Microbiology. 71(9) (2005) 5544-5550.

[45] K.T. Konstantinidis, A. Ramette, J.M. Tiedje, The bacterial species definition in the genomic era, Philosophical Transactions of the Royal Society B: Biological Sciences. 361(1475) (2006) 1929-1940.

[46] T.R. Scheublin et al., Nonlegumes, legumes and root nodules harbor different arbuscular mycorrhizal fungal communities, Applied and Environmental Microbiology. 70(10) (2004) 6240-6246.

[47] N.C.M. Gomes et al., Dynamics of fungal communities in bulk and maize rhizosphere soil in the tropics. Applied and Environmental Microbiology, 69(7) (2003) 3758-3766.

[48] G. Wang et al., Effect of soil type and soybean genotype on fungal community in soybean rhizosphere during reproductive growth stages, Plant and Soil. 317 (2009) 135-144.

[49] A. Houlden et al., Influence of plant developmental stage on microbial community structure and activity in the rhizosphere of three field crops, FEMS Microbiology Ecology. 65 (2008) 193-201.

[50] Y. Xu et al., Bacterial communities in soybean rhizosphere in response to soil type, soybean genotype, and their growth stage, Soil Biology and Biochemistry. 41 (2009) 919-925.

[51] A. Sugiyama et al., Changes in the bacterial community of soybean rhizospheres during growth in the field, PLoS One. 9(6) (2014) doi: 10.1371/journal.pone.0100709.

[52] P. Garbeva, J.A. van Veen, J.D. van Elsas, Microbial diversity in soil: selection of microbial populations by plant and soil type and implications for disease suppressiveness, Annual Review of Phytopathology. 42 (2004) 243-270.

[53] J. Swinnen, J.A.Van Veen, R. Merckx, ${ }^{14} \mathrm{C}$ pulse-labelling of field-grown spring wheat: an evaluation of its use in rhizosphere carbon budget estimations, Soil Biology and Biochemistry. 26(2) (1994) 161-170.

[54] J.M. Chaparro et al., Root exudation of phytochemicals in Arabidopsis follows specific patterns that are developmentally programmed and correlate with soil microbial functions, PLoS One. 8(2) (2013) doi: 10.1371/journal.pone.0055731.

[55] O. Inceoğlu et al., Effects of plant genotype and growth stage on the betaproteobacterial communities associate with different potato cultivars in two fields, Applied and Environmental Microbiology. 76(11) (2010) 3675-3684.

[56] Q. Tian et al., Land-use types and soil chemical properties influence soil microbial communities in the semiarid Loess Plateau region in China, Scientific Reports. 7(45289) (2017) doi: 10.1038/srep45289.

[57] C. Zhao et al., Soil microbial community composition and respiration along an experimental precipitation gradient in a semiarid steppe, Scientific Reports. 6(24317) (2016) doi: $10.1038 /$ srep24317.

[58] C.C. Lo, Effect of pesticides on soil microbial community, Journal of Environmental Science and Health, Part B. 45(5) (2010) 348-359.

[59] A.D. Rovira, Root excretions in relation to the rhizosphere effect, Plant and Soil. 11(1) (1959) $53-64$.

[60] Z. Rengel, Genetic control of root exudation, Plant and Soil. 245(1) (2002) 59-70. 
[61] J.A. Schweitzer et al., Plant-soil microorganism interactions: heritable relationship between plant genotype and associated soil microorganisms, Ecology. 89(3) (2008) 773-781.

[62] S.A. Micallef, M.P. Shiaris, A. Colon-Carmona, Influence of Arabidopsis thaliana accessions on rhizobacterial communities and natural variation in root exudates, Journal of Experimental Botany. 60(6) (2009) 1729-1742.

[63] S.A. Micallef et al., Plant age and genotype impact the progression of bacterial community succession in the Arabidopsis rhizosphere, Plant Signaling \& Behavior. 4(8) (2009) 777-780.

[64] Santos-Medellin et al., Drought stress results in a compartment-specific restructuring of the rice root-associated microbiomes, American Society for Microbiology. mBio 8:e00764-17 (2017) doi: 10.1128/mBio.00764-17.

[65] J.M. Raaijmakers et al., The rhizosphere: a playground and battlefield for soilborne pathogens and beneficial microorganisms, Plant and Soil. 321(1) (2009) 341-361.

[66] A. Kaisermann et al., Fungal communities are more sensitive indicators to non-extreme soil moisture variations than bacterial communities, Applied Soil Ecology. 86 (2015) 158-164.

[67] P.E. Busby et al., Research priorities for harnessing plant microbiomes in sustainable agriculture, PLoS Biology. 15(3) (2017) doi: 10.1371/journal. pbio.2001793.

[68] J.M. Barea, Future challenges and perspectives for applying microbial biotechnology in sustainable agriculture based on a better understanding of plant-microbiome interactions, Journal of Soil Science and Plant Nutrition. 15(2) (2015) 261-282. 